\title{
Piezoelectric Theory for Finite Element Analysis of Ultrasonic Motors
}

Federal Manufacturing \& Technologies

\author{
James D. Emery
}

KCP-613-5953

RECEIVED

JUL $1^{4}$ 1997

Published June 1997

O. STI

Topical Report

Charles P. Mentesana, Project Leader

Approved for public release; distribution is unlimited.

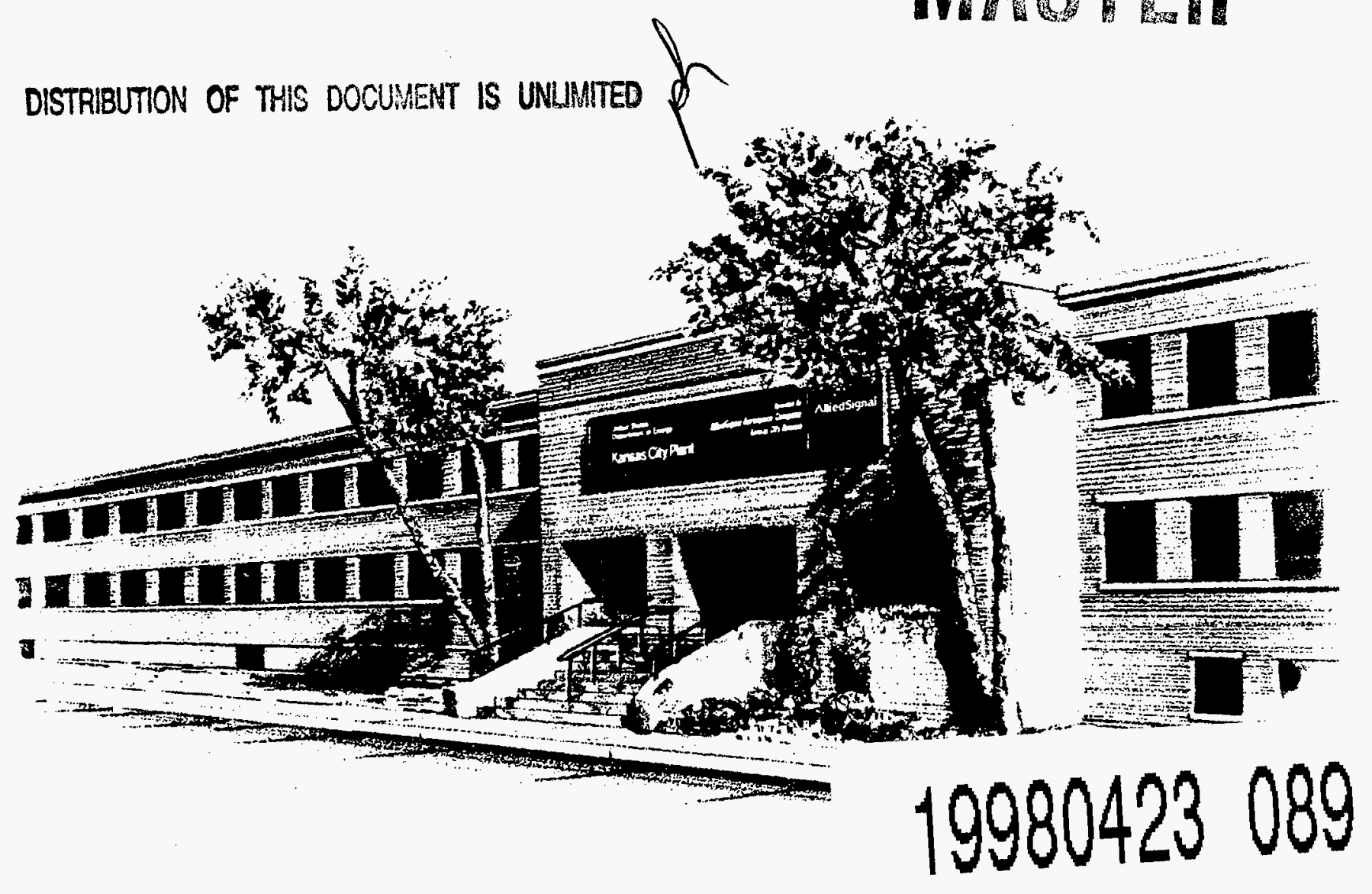

Prepared Under Contract Number DE-AC04-76-DP00613 for the

United States Department of Energy

AlliedSignal

A E R O S P A C E 


\section{DISCLAIMER}

This report was prepared as an account of work sponsored by an agency of the United States Government. Neither the United States Government nor any agency thereof, nor any of their employees, makes any warranty, express or implied, or assumes any legal liability or responsibility for the accuracy, completeness, or usefulness of any information, apparatus, product, or process disclosed, or represents that its use would not infringe privately owned rights. Reference herein to any specific commercial product, process, or service by trade names, trademark, manufacturer, or otherwise, does not necessarily constitute or imply its endorsement, recommendation, or favoring by the United States Government or any agency thereof. The views and opinions of authors expressed herein do not necessarily state or reflect those of the United States Government or any agency thereof.

Printed in the United States of America.

This report has been reproduced from the best available copy.

Available to DOE and DOE contractors from the Office of Scientific and Technical Information, P. O. Box 62, Oak Ridge, Tennessee 37831; prices available from (615) 576-8401, FTS 626-8401.

Available to the public from the National Technical Information Service, U. S. Department of Commerce, 5285 Port Royal Rd., Springfield, Virginia 22161.

A prime contractor with the United States Department of Energy under Contract Number DE-ACO4-76-DP00613.
AlliedSignal Inc. Federal Manufacturing \& Technologies P. O. Box 419159 Kansas City, Missouri 64141-6159 
KCP-613-5953

Distribution Category UC-705

Approved for public release; distribution is unlimited.

\section{PIEZOELECTRIC THEORY FOR FINITE ELEMENT} ANALYSIS OF ULTRASONIC MOTORS

James D. Emery

Published June 1997

Topical Report

Charles P. Mentesana, Project Leader 


\section{CONTENTS}

\section{Section}

Abstract

Summary

Discussion

Scope and Purpose

Prior and Related Work

2

0.1 Introduction

0.2 The Linear Piezoelectric Equations

0.3 Piezoelectric Ceramics Constants and One Dimensional Equations

0.4 The Stress Form of the Piezoelectric Matrix

0.5 Three Systems of Notation For The Piezoelectric Equations: Physics (IRE), ABAQUS, and ANSYS

0.6 Deriving the Tensor Stress Form of the Piezoelectric Equations From the Strain Form

0.7 Orthotropic Material

0.8 Poling and Piezoelectric Ceramics.

0.9 The Equality of Direct and Converse Piezo Coefficients

0.10 Typical Values of Piezoelectric Parameters.

0.11 Piezoelectric Current and Impedance From A Finite Element Calculation.........

0.12 Piezoelectric Cube Example

0.13 Generating Ferroelectric Hysteresis Curves

0.14 The Strain Hysteresis Curve 
0.15 Relaxors

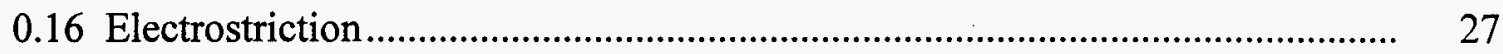

0.17 The Conversion Program: pzansys.ftn ............................................................. 27

0.18 Example: Parameter Conversion Using Compliance Components .................... 28

0.19 Example: Parameter Conversion Using Four Independent Elasticity Components ................................................................................... 31

0.20 Example, Orthotropic Elastic Constants ...................................................... 34

0.21 Program Listing of pzansys.ftn Program ........................................................ 37

0.22 Location of Piezoelectric Information In ANSYS Manuals .............................. 58

0.23 ANSYS Comparison For A Composite Piezoelectric Transducer: Example VM176 ......................................................................................... 59

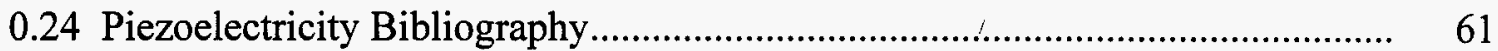




\begin{abstract}
We present the fundamental equations of piezoelectricity and references. We show how a second form of the equations and a second set of coefficients can be found, through inversions involving the elasticity tensor. We show how to compute the clamped permittivity matrix from the unclamped matrix. We list the program pzansys.fin and present examples of its use. This program does the conversions and calculations needed by the finite element program ANSYS.
\end{abstract}

\title{
Summary
}

Ultrasonic traveling wave motors operate by supplying electrical power to a piezoelectric ceramic. The piezoelectric element supplies energy to a stator. The stator vibrates in two natural resonant modes in such a way as to generate traveling waves in the stator. These traveling waves cause the motion of a rotor.

Finite element analysis is required to find the natural modes of vibration of the stator, and to model the operation of the motor, so that an optimal design may be found. It is necessary to transform piezoelectric, elastic, and permittivity tensors for use in the FEM codes.

An understanding of the relationship between the electrical and mechanical field variables is needed in order to properly model these devices. We present the basic piezoelectric electromechanical equations and tensors. A program is presented to perform the conversion calculations and to calculate the necessary information required by the ANSYS finite element program. We give a general bibliography relating to piezoelectric motors. 


\section{Discussion}

\section{Scope and Purpose}

The purpose of this work is to support the design of piezoelectric motors through FEM analysis. The piezoelectric motors are to be used in new stronglink mechanisms and may be used in various other device components. These new designs are made necessary by new requirements.

\section{Prior and Related Work}

There are several reports explaining in more detail the operation and design of these piezoelectric motors and their use in devices. See the AlliedSignal Federal Manufacturing \& Technologies (FM\&T) reports by Mentesana, and by Pressly and Mentesana in the Bibliography. 


\subsection{Introduction}

We shall show how to derive the stress form of the piezoelectric equations from the strain form, and we shall show how to find the clamped permittivity matrix from the unclamped matrix. These conversions are required for finite element programs because in such programs equations are solved for the elastic displacements, and so the strains rather than the stresses are the independent variables. We shall do the basic derivation three times in the following sections. We shall first treat the one dimensional equation. In later sections we shall treat the matrix case and the full tensor case. These derivations are conceptually the same.

\subsection{The Linear Piezoelectric Equations}

A piezoelectric ceramic is a ferroelectric material. It exhibits hysteresis and has nonlinear behavior. When this material is poled (placed in a strong electric field), it attains a permanently polarized state. For a small variation in the electric field, it behaves approximately linearly near that state.

The linear piezoelectric equations are written in two different forms. In the more common form, which is called the strain form, the strain tensor $\varepsilon_{i j}$ and the electric polarization vector $P_{i}$ are each written as linear functions of the electric field vector $E_{i}$ and the stress tensor $\sigma_{i j}$. These equations are

$$
\epsilon_{i j}=E_{k} d_{k i j}+c_{i j k l}^{\prime} \sigma_{k l}
$$

and

$$
P_{i}=\epsilon_{0} \chi_{i j} E_{j}+d_{i j k} \sigma_{j k} \text {. }
$$

The $d_{i j k}$ are the components of the piezoelectric tensor (strain coefficients). The $c_{i j k l}^{\prime}$ are the components of the inverse elastic tensor. The constant $\epsilon_{0}$ is the permittivity of free space. The $\chi_{i j}$ are the components of the electric susceptibility tensor. In the direct piezoelectric effect, when a piezoelectric material is put under a stress, the material becomes electrically polarized and surface charges appear. The direct piezoelectric effect is

$$
P_{i}=d_{i j k} \sigma_{j k}
$$


which is obtained from the second equation, when the external electric field is zero.

In the converse piezoelectric effect, when a piezoelectric material is put in an external electric field (voltages applied to electrodes), the material experiences a strain. The converse piezoelectric effect is

$$
\varepsilon_{i j}=E_{k} d_{k i j},
$$

which is obtained from the first equation, when there are no external forces and the stress is zero.

The fact that the coefficients for both the direct effect and the converse effect are the same is a consequence of conservation of energy. This fact can be established by a thermodynamic argument (See Nye). Because of various symmetries in the tensor indices, the equations have matrix forms. Let us define an index function $f:(i, j)->k$ that takes a pair of indices and produces a single index. The function $f$ takes values as follows: $f(1,1)=$ $1, f(2,2)=2, f(3,3)=3, f(2,3)=4, f(1,3)=5, f(1,2)=6$ The function is symmetric, $f(i, j)=f(j, i)$, and so $f(3,2)=4, f(3,1)=5, f(2,1)=6$. This is the Physics and The Institute of Radio Engineers assignment function. We define this function with a table:

\begin{tabular}{||l|l|l|l||}
\hline$f$ & 1 & 2 & 3 \\
\hline 1 & 1 & 6 & 5 \\
\hline 2 & 6 & 2 & 4 \\
\hline 3 & 5 & 4 & 3 \\
\hline
\end{tabular}

This index assignment is the one most often used in elasticity theory to convert the second rank stress and strain tensors to six component vectors. Although this is the usual convention, the following assignment defined by function $g$ is used sometimes (ABAQUS).

\begin{tabular}{|c||c|c|c||}
\hline $\mathbf{g}$ & 1 & 2 & 3 \\
\hline \hline 1 & 1 & 4 & 5 \\
\hline 2 & 4 & 2 & 6 \\
\hline 3 & 5 & 6 & 3 \\
\hline
\end{tabular}

A third index function is also used. The function, which we call $h$ is used by the finite element program ANSYS. 


\begin{tabular}{|l||l|l|l|}
\hline $\mathrm{h}$ & 1 & 2 & 3 \\
\hline \hline 1 & 1 & 4 & 6 \\
\hline 2 & 4 & 2 & 5 \\
\hline 3 & 6 & 5 & 3 \\
\hline
\end{tabular}

Warning! These differences in index assignment will change the matrices such as $c, d, e$.

The matrix components of the piezoelectric tensor are $d_{i, f(i, j)}$ and are either equal to the tensor component itself, when $i=j$, or to twice the component. This will be explained below.

There is a second form of the piezoelectric equations, which is called the stress form.

The stress tensor $\sigma_{i j}$ and the electric displacement vector $D_{i}$, are each written as linear functions of the electric field vector $E_{i}$ and the strain tensor $\varepsilon_{i j}$. These equations are

$$
\sigma_{i j}=c_{i j k l} \varepsilon_{k l}-E_{k} e_{k i j}
$$

and

$$
D_{i}=e_{i j k} \varepsilon_{j k}+\epsilon_{i j} E_{j} \text {. }
$$

The $c_{i j k l}$ are the components of the elastic tensor. The $e_{i j k}$ are the components of the piezoelectric tensor (stress coefficients). The $\epsilon_{i j}$ are the components of the permittivity tensor.

These equations are suitable for finite element programs because in these programs the displacements and hence the strains are the independent variables, whereas the boundary conditions are given as force loadings, that is as stresses. It will be shown below that the piezoelectric stress coefficients and the strain coefficients are related as follows:

$$
e_{i j k}=c_{j k l m} d_{i l m} \text {. }
$$

Notation varies greatly in the field of piezoelectricity. In a following section we will summarize the notation used in physics, and in two finite element programs ABAQUS and ANSYS. 


\subsection{Piezoelectric Ceramics Constants and One Dimensional Equations}

The principal references for this section are: Jaffe, Cook and Jaffe, Piezoelectric Ceramics, and the Morgan Matroc document Guide To Modern Piezoelectric Ceramics.

The original research on piezoelectric materials was conducted with parallel plate capacitors, and the problem was treated as one dimensional. So the strain form of the equations considered were

$$
\begin{aligned}
& \varepsilon=E d+c^{-1} \sigma \\
& P=\epsilon_{0} \chi E+d \sigma,
\end{aligned}
$$

where the quantities are in the 3 direction. From the definition of the electric displacement

$$
D=P+\epsilon_{0} E=\epsilon_{0}(\chi+1) E+d \sigma=\epsilon^{\sigma} E+d \sigma .
$$

So we have an alternate form

$$
D=\epsilon^{\sigma} E+d \sigma .
$$

Here $\epsilon^{\sigma}$ is the permittivity at constant stress (unclamped).

The second set of piezoelectric equations (stress form) may be obtained from the first set (strain form). Solving the first equation for the stress, we have

$$
\sigma=c \varepsilon-c d E=c \varepsilon-e E .
$$

Making this substitution for $\sigma$ in the alternate form of the second equation of the first set, we get the second equation of the second set.

$$
\begin{gathered}
D=\epsilon^{\sigma} E+d(c \varepsilon-e E)=\epsilon E+e \varepsilon, \\
=\left(\epsilon^{\sigma}-d e\right) E+d c \varepsilon \\
=\epsilon^{e} E+e \varepsilon,
\end{gathered}
$$

where the piezoelectric coefficient $e=c d$. Here $\epsilon^{e}$ is the permittivity at constant stress (unclamped). 
The coefficients may be defined as partial derivatives. For example,

$$
d=\left(\frac{\partial \varepsilon}{\partial E}\right)_{\sigma},
$$

where the subscript $\sigma$ means that $\varepsilon$ is a function of $E$ and $\sigma$, where $\sigma$ is held constant in computing the partial derivative. Similarly we have

$$
d=\left(\frac{\partial P}{\partial \sigma}\right)_{E}
$$

The constant $g$ is defined by

$$
g=\left(-\frac{\partial E}{\partial \sigma}\right)_{\varepsilon}=\left(\frac{\partial \varepsilon}{\partial D}\right)_{\sigma}
$$

We have

$$
E=\frac{1}{\epsilon}(D-d \sigma)
$$

so

$$
g=-\left(\frac{\partial E}{\partial \sigma}\right)_{\varepsilon}=\frac{d}{\epsilon} .
$$

The constant $e$ is defined by

$$
e=-\left(\frac{\partial \sigma}{\partial E}\right)_{e}=\left(\frac{\partial D}{\partial \varepsilon}\right)_{E}
$$

The poled ceramic is an orthotropic material with a plane of symmetry whose normal is in the poled direction. Further it is symmetric with respect to any rotation about the poling direction. Performing a reflection through the symmetry plane, some of the strain components and stress components are maintained in sign and some others are changed in sign. Writing the various components of stress as functions of strain, in the two coordinate systems, we find that the proper signs can be maintained only if some of the elastic coefficients are zero (see pp62-64 Sokolnikoff Mathematical Theory of Elasticity). Carrying out rotation transformations about the poling axis ( 3 direction) we find further conditions on the elasticity coefficients. We have only the following independent elastic coefficients ( $\mathrm{Jaffe}$ et al, p20)

$$
c_{11}, c_{33}, c_{44}, c_{12}, c_{13}
$$


We have

$$
c_{22}=c_{11}, c_{55}=c_{44}, c_{66}=2\left(c_{11}-c 12\right), c_{23}=c_{13} .
$$

Coefficients which are not in the upper 3-dimensional submatrix or on the main diagonal are zero.

The independent piezoelectric coefficients are

$$
d_{33}, d_{31}, d_{15}
$$

We have

$$
d_{32}=d_{31}, d_{24}=d_{15}
$$

All other coefficients are zero.

The independent dielectric coefficients are

$$
K_{11}, K_{33}
$$

We have

$$
K_{22}=K_{11}
$$

All other coefficients are zero.

The permittivity is

$$
\epsilon_{i j}=\epsilon_{0} K_{i j}
$$

The electromechanical coupling constant is defined in terms of the ratio of stored electrical to stored mechanical energy. Let $Q_{\text {mech }}$ be the electrical energy converted to mechanical energy and let $Q_{\text {input }}$ be the electrical energy input. Then the electromechanical coupling factor is

$$
k^{2}=\frac{Q_{\text {mech }}}{Q_{\text {input }}}
$$

It is claimed (Jaffe et al p7) that the relation between the unclamped dielectric constant $K^{\sigma}$ and the clamped dielectric constant $K^{\epsilon}$ is

$$
K^{\varepsilon}=K^{\sigma}\left(1-k^{2}\right)
$$

Because $0<k<1$, the clamped dielectric constant is smaller than the clamped constant

$$
K^{e}<K^{\sigma}
$$




\subsection{The Stress Form of The Piezoelectric Matrix}

Given the strain form of the piezoelectric equations, we can convert to the stress form and give expressions for the three independent e tensor parameters. In matrix form we have

$$
\begin{gathered}
\varepsilon=d^{T} E+c^{-1} \sigma \\
P=\epsilon_{0} \chi E+d \sigma
\end{gathered}
$$

From the first equation multiplying by the elasticity matrix $c$ we have

$$
c \varepsilon=c d^{T} E+\sigma
$$

so solving for the stress matrix $\sigma$ we have

$$
\begin{aligned}
\sigma & =c \varepsilon-c d^{T} E \\
& =c \varepsilon-e E
\end{aligned}
$$

where the matrix $e$ is defined as the product of $c$ and the transpose of $d$

$$
e=c d^{T}
$$

We have

$$
e^{T}=\left(c d^{T}\right)^{T}=c^{T} d=c d
$$

The last equality follows because $c$ is symmetric. From the second equation

$$
\begin{gathered}
D=P+\epsilon_{0} E=\epsilon_{0} \chi E+d \sigma+\epsilon_{0} E \\
=\epsilon_{0}(\chi+I) E+d \sigma \\
=\epsilon^{\sigma} E+d \sigma
\end{gathered}
$$

where $\epsilon^{\sigma}$ is the permittivity at constant stress (unclamped permittivity). Substituting the expression for the stress $\sigma$ from above

$$
\begin{gathered}
D=\epsilon^{\sigma} E+d(c \varepsilon-e E) \\
=\left(\epsilon^{\sigma}-d e\right) E+d c \varepsilon
\end{gathered}
$$




$$
=\epsilon^{\epsilon} E+e^{T} \varepsilon,
$$

where

$$
\epsilon^{e}=\epsilon^{\sigma}-d e
$$

is the permittivity at constant strain (clamped permittivity). In the previous section we saw that the elastic matrix $c$ has 5 independent parameters and $d$ has three independent parameters. We have

$$
c=\left[\begin{array}{cccccc}
c_{11} & c_{12} & c_{13} & 0 & 0 & 0 \\
c_{12} & c_{11} & c_{13} & 0 & 0 & 0 \\
c_{13} & c_{13} & c_{33} & 0 & 0 & 0 \\
0 & 0 & 0 & c_{44} & 0 & 0 \\
0 & 0 & 0 & 0 & c_{44} & 0 \\
0 & 0 & 0 & 0 & 0 & 2\left(c_{11}-c_{12}\right)
\end{array}\right]
$$

and

$$
d=\left[\begin{array}{cccccc}
0 & 0 & 0 & 0 & d_{15} & 0 \\
0 & 0 & 0 & d_{15} & 0 & 0 \\
d_{31} & d_{31} & d_{33} & 0 & 0 & 0
\end{array}\right]
$$

Then the piezoelectric stress matrix is

$$
\begin{aligned}
e=c d^{T}= & {\left[\begin{array}{cccccc}
c_{11} & c_{12} & c_{13} & 0 & 0 & 0 \\
c_{12} & c_{11} & c_{13} & 0 & 0 & 0 \\
c_{13} & c_{13} & c_{33} & 0 & 0 & 0 \\
0 & 0 & 0 & c_{44} & 0 & 0 \\
0 & 0 & 0 & 0 & c_{44} & 0 \\
0 & 0 & 0 & 0 & 0 & 2\left(c_{11}-c_{12}\right)
\end{array}\right]\left[\begin{array}{ccc}
0 & 0 & d_{31} \\
0 & 0 & d_{31} \\
0 & 0 & d_{33} \\
0 & d_{15} & 0 \\
d_{15} & 0 & 0 \\
0 & 0 & 0
\end{array}\right] } \\
& =\left[\begin{array}{cccc}
0 & 0 & c_{11} d_{31}+c_{12} d_{31}+c_{13} d_{33} \\
0 & 0 & c_{12} d_{31}+c_{11} d_{31}+c_{13} d_{33} \\
0 & 0 & c_{13} d_{31}+c_{13} d_{31}+c_{33} d_{33} \\
0 & c_{44} d_{15} & 0 \\
c_{44} d_{15} & 0 & 0 \\
0 & 0 & 0
\end{array}\right]
\end{aligned}
$$




$$
=\left[\begin{array}{ccc}
0 & 0 & e_{13} \\
0 & 0 & e_{13} \\
0 & 0 & e_{33} \\
0 & e_{42} & 0 \\
e_{42} & 0 & 0 \\
0 & 0 & 0
\end{array}\right]
$$

So the three independent piezo $e$ parameters are $e_{13}, e_{33}, e_{42}$. (Warning! The $e$ matrix is sometimes defined as the transpose of this $e$ matrix.)

Explicitly we have

$$
\begin{aligned}
& e_{13}=\left(c_{11}+c_{12}\right) d_{31}+c_{13} d_{33} \\
& e_{33}=\left(c_{13}+c_{13}\right) d_{31}+c_{33} d_{33}
\end{aligned}
$$

and

$$
e_{42}=c_{44} d_{15} \text {. }
$$

These equations are easily solved for $d_{33}, d_{31}$ and $d_{15}$ in terms of the three independent $e$ and five independent $c$ coefficients.

\subsection{Three Systems of Notation For The Piezo- electric Equations: Physics (IRE), ABAQUS, and ANSYS}

The index function $f(i j)$, which maps two indices to one, in the way that is conventional in elasticity theory, was defined in the previous section, as was $g(i j)$. Here is a table showing the notation most commonly used in physics (References, Nye, Auld, Cady, IRE (The Institute of Radio Engineers Standard) ANSYS Procedures p8-15, ), and in the finite element systems ABAQUS (Reference: Theory manual, section 3.10.1), and ANSYS (Reference: Theory manual, Piezoelectrics chapter). 


\begin{tabular}{||c|c|c|c||}
\hline Variable & Physics & ABAQUS & ANSYS \\
\hline \hline Electric Field Vector & $E_{i}$ & $E_{i}$ & $E_{i}$ \\
\hline Electric Polarization Vector & $P_{i}$ & $P_{i}$ & $P_{i}$ \\
\hline Electric Displacement Vector & $D_{i}$ & $q_{i}$ & $D_{i}$ \\
\hline Stress Tensor & $\sigma_{i j}$ & $\sigma_{i j}$ & $\sigma_{i j}$ \\
\hline Stress Vector & $\sigma_{k}=\sigma_{f(i j)}$ & - & $T_{k}$ \\
\hline Strain Tensor & $\varepsilon_{i j}$ & $\varepsilon_{i j}$ & - \\
\hline Strain Vector & $\varepsilon_{k}$ & - & $S_{k}$ \\
\hline Electric Permittivity Tensor & $\epsilon_{i j}$ & $D_{i j}^{\phi}$ & $\epsilon_{i j}$ \\
\hline Electric Susceptibility Tensor & $\chi_{i j}$ & - & - \\
\hline Elasticity Tensor & $c_{i j k l}$ & $D_{i j k l}$ & $c_{i j k l}$ \\
\hline Elasticity Matrix & $c_{m n}=c_{f(i j) f(k l)}$ & - & $c_{m n}$ \\
\hline Inverse Elasticity Tensor & $c_{i j k l}^{\prime}$ & - & $c_{i j k l}^{\prime}$ \\
\hline Piezoelectric Tensor (strain) & $d_{i, j k}$ & $d_{i, j k}^{\phi}$ & $d_{i, j k}$ \\
\hline Piezoelectric Matrix (strain) & $d_{i, m}=d_{i, f(j k)}$ & $d_{i, m}=d_{i, g(j k)}$ & $d_{i, m}$ \\
\hline Piezoelectric Tensor (stress) & $e_{i, j k}$ & $e_{i, j k}^{\phi}$ & $e_{j k, i}$ \\
\hline Piezoelectric Matrix (stress) & $e_{i, m}=e_{i, f(j k)}$ & $e_{i, m}=e_{i, g(j k)}$ & $e_{m, i}$ \\
\hline
\end{tabular}

The engineering strain coefficients are written as $\gamma_{i j}$. They differ from the $\varepsilon_{i j}$, in that the shear coefficients are doubled in value.

Note: the physics notation for $e_{i j k}$ is defined in equation 8.40 of Auld. Nye does not introduce the piezoelectric $e$ coefficients. The Cady book is very old and one can obtain piezoelectric constant notation only by implication. Note: The ANSYS definition of the $e$ matrix and tensor is the transpose of the physics and ABAQUS definition. Thus the ANSYS e matrix is 6 by 3 , whereas the physics $e$ matrix is 3 by 6 .

The two ABAQUS tensor equations are:

$$
\begin{gathered}
\sigma_{i j}=D_{i j k l} \varepsilon_{k l}-e_{m i j}^{\phi} E_{m} \\
\text { (or alternately: } \left.\sigma_{i j}=D_{i j k l} \varepsilon_{k l}-D_{i j k l} d_{m k l}^{\phi} E_{m}\right) \\
q_{i}=e_{i j k}^{\phi}+D_{i j}^{\phi} E_{j} .
\end{gathered}
$$

The ANSYS matrix equations are:

$$
T=c S-e E
$$




$$
D=e^{T} S+\epsilon E .
$$

The Physics matrix equations are:

$$
\begin{gathered}
\sigma=c \varepsilon-e^{T} E, \\
D=e \varepsilon+\epsilon E .
\end{gathered}
$$

Again note that the ANSYS $e$ definition and the physics $e$ definition are transposes of one another.

Here are the ANSYS matrices written out:

$$
\begin{aligned}
& T=\sigma=\left[\begin{array}{c}
\sigma_{1} \\
\sigma_{2} \\
\cdots \\
\sigma_{6}
\end{array}\right] \\
& S=\varepsilon=\left[\begin{array}{c}
\varepsilon_{1} \\
\varepsilon_{2} \\
\ldots \\
\varepsilon_{6}
\end{array}\right] \\
& E=\left[\begin{array}{l}
E_{1} \\
E_{2} \\
E_{3}
\end{array}\right] \\
& D=\left[\begin{array}{c}
D_{1} \\
D_{2} \\
D_{3}
\end{array}\right] \\
& c=\left[\begin{array}{cccccc}
c_{11} & c_{12} & c_{13} & 0 & 0 & 0 \\
c_{21} & c_{22} & c_{23} & 0 & 0 & 0 \\
c_{31} & c_{32} & c_{33} & 0 & 0 & 0 \\
0 & 0 & 0 & c_{44} & 0 & 0 \\
0 & 0 & 0 & 0 & c_{55} & 0 \\
0 & 0 & 0 & 0 & 0 & c_{66}
\end{array}\right]
\end{aligned}
$$




$$
\begin{aligned}
& e=\left[\begin{array}{lll}
e_{11} & e_{12} & e_{13} \\
e_{21} & e_{22} & e_{23} \\
e_{31} & e_{32} & e_{33} \\
e_{41} & e_{42} & e_{43} \\
e_{51} & e_{52} & e_{53} \\
e_{61} & e_{62} & e_{63}
\end{array}\right] \\
& \epsilon=\left[\begin{array}{ccc}
\epsilon_{11} & 0 & 0 \\
0 & \epsilon_{22} & 0 \\
0 & 0 & \epsilon_{22}
\end{array}\right]
\end{aligned}
$$

We will show in the next section that (physics notation)

$$
e_{i j k}=c_{j k l m} d_{i l m} \text {. }
$$

\subsection{Deriving the Tensor Stress Form of the Piezoelectric Equations From the Strain Form}

We have already done this derivation in a previous section for the matrix forms of the piezoelectric equations. Here we will repeat this for the tensor forms of the equations. We start with the strain form of the piezoelectric equations

$$
\varepsilon_{i j}=E_{k} d_{k i j}+c_{i j k l}^{\prime} \sigma_{k l}
$$

and

$$
P_{i}=\epsilon_{0} \chi_{i j} E_{j}+d_{i j k} \sigma_{j k} .
$$

Let $c_{p q i j}$ be the elasticity tensor. Because $c^{\prime}$ is its inverse, we have

$$
c_{p q i j} c_{i j k l}^{\prime}=\delta_{k}^{p} \delta_{l}^{q}
$$

Then multiplying the first equation by $c_{p q i j}$ and summing we get

$$
c_{p q i j} \varepsilon_{i j}=c_{p q i j} E_{k} d_{k i j}+c_{p q i j} c_{i j k l}^{\prime} \sigma_{k l}
$$


which becomes

$$
c_{p q i j} \varepsilon_{i j}=c_{p q i j} E_{k} d_{k i j}+\sigma_{p q} .
$$

We let

$$
e_{k p q}=c_{p q i j} d_{k i j}
$$

Then

$$
\sigma_{p q}=c_{p q r s} \varepsilon_{r s}-e_{m p q} E_{m} .
$$

The equation relating electric displacement $D$, electric polarization $P$, and the macro electric field $E$ is

$$
D_{i}=P_{i}+\epsilon_{0} E_{i} .
$$

Substituting for the polarization from the second piezoelectric equation above, we have

$$
D_{i}=\epsilon_{0} \chi_{i j} E_{j}+d_{i j k} \sigma_{j k}+\epsilon_{0} E_{i} .
$$

We write this as

$$
\begin{aligned}
D_{i}= & \epsilon_{0}\left(\chi_{i j}+\delta_{i j}\right) E_{j}+d_{i j k} \sigma_{j k} \\
& =\epsilon_{i j}^{\sigma} E_{j}+d_{i p q} \sigma_{p q},
\end{aligned}
$$

where $\epsilon_{i j}^{\sigma}$ is the zero stress (unclamped ) permittivity. Substituting our previously derived expression for the stress, we get

$$
\begin{gathered}
D_{i}=\epsilon_{i m}^{\sigma} E_{m}+d_{i p q}\left(c_{p q r s} \varepsilon_{r s}-e_{m p q} E_{m}\right) \\
=\left(\epsilon_{i m}^{\sigma}-d_{i p q} e_{m p q}\right) E_{m}+d_{i p q} c_{p q r s} \varepsilon_{r s} \\
=e_{i r s} \varepsilon_{r s}+\epsilon_{i m}^{\epsilon} E_{m}
\end{gathered}
$$

where

$$
\epsilon_{i m}^{\varepsilon}=\epsilon_{i m}^{\sigma}-d_{i p q} e_{m p q}
$$

is the zero strain (clamped) permittivity. We have assumed that $c_{p q r s}=c_{r s p q}$. This is the case when the internal energy of the material is a function of the values $\sigma, \varepsilon, D$, and $E$, and not dependent on the path through which the state was reached, that is, when the internal energy is an exact differential in the thermodynamic sense. Therefore redefining the dummy indices, we have the stress version of the piezoelectric equations:

$$
\sigma_{i j}=c_{i j k l} \varepsilon_{k l}-E_{k} e_{k i j},
$$


and

$$
D_{i}=e_{i j k} \varepsilon_{j k}+\epsilon_{i j}^{e} E_{j}
$$

The matrix forms of these equations are:

$$
\begin{aligned}
& \sigma=c \varepsilon-e^{T} E, \\
& D=e \varepsilon+\epsilon^{\varepsilon} E .
\end{aligned}
$$

\subsection{Orthotropic Material}

An orthotropic problem is one in which the material properties are symmetric with respect to 3 mutually orthogonal planes (See Sokolnikoff p62). A piezoelectric ceramic such as PZT is orthotropic, but has even more symmetry. It is invariant to any rotation about the poled axis. By applying various symmetry transformations, and invariance properties, one finds that many of the elastic constants must be zero. The elastic matrix becomes

$$
c=\left[\begin{array}{cccccc}
c_{11} & c_{12} & c_{13} & 0 & 0 & 0 \\
c_{21} & c_{22} & c_{23} & 0 & 0 & 0 \\
c_{31} & c_{32} & c_{33} & 0 & 0 & 0 \\
0 & 0 & 0 & c_{44} & 0 & 0 \\
0 & 0 & 0 & 0 & c_{55} & 0 \\
0 & 0 & 0 & 0 & 0 & c_{66}
\end{array}\right]
$$

The inverse matrix is

$$
c^{\prime}=c^{-1}=\left[\begin{array}{cccccc}
1 / E_{1} & -\nu_{21} / E_{2} & -\nu_{31} / E_{3} & 0 & 0 & 0 \\
-\nu_{12} / E_{1} & 1 / E_{2} & -\nu_{32} / E_{3} & 0 & 0 & 0 \\
-\nu_{13} / E_{1} & -\nu_{23} / E_{2} & 1 / E_{3} & 0 & 0 & 0 \\
0 & 0 & 0 & 1 /\left(2 \mu_{32}\right) & 0 & 0 \\
0 & 0 & 0 & 0 & 1 /\left(2 \mu_{31}\right) & 0 \\
0 & 0 & 0 & 0 & 0 & 1 /\left(2 \mu_{12}\right)
\end{array}\right] .
$$

The Poisson ratio, $\nu_{i j}$, is the ratio of the negative of the strain in the $x_{j}$ direction, to the strain in the $x_{i}$ direction, for a normal stress in the $x_{i}$ direction. For example, if the only nonzero stress component is $\sigma_{1}$, then 


$$
\begin{gathered}
{\left[\begin{array}{cccccc}
1 / E_{1} & -\nu_{21} / E_{2} & -\nu_{31} / E_{3} & 0 & 0 & 0 \\
-\nu_{12} / E_{1} & 1 / E_{2} & -\nu_{32} / E_{3} & 0 & 0 & 0 \\
-\nu_{13} / E_{1} & -\nu_{23} / E_{2} & 1 / E_{3} & 0 & 0 & 0 \\
0 & 0 & 0 & 1 /\left(2 \mu_{32}\right) & 0 & 0 \\
0 & 0 & 0 & 0 & 1 /\left(2 \mu_{31}\right) & 0 \\
0 & 0 & 0 & 0 & 0 & 1 /\left(2 \mu_{12}\right)
\end{array}\right]\left[\begin{array}{c}
\sigma_{1} \\
0 \\
0 \\
0 \\
0 \\
0
\end{array}\right]} \\
=\left[\begin{array}{c}
\sigma_{1} / E_{1} \\
\left(-\sigma_{1} \nu_{12}\right) / E_{1} \\
\left(-\sigma_{1} \nu_{13}\right) / E_{1} \\
0 \\
0 \\
0 \\
0 \\
\varepsilon_{1} \\
\varepsilon_{2} \\
\varepsilon_{3} \\
0 \\
0 \\
0
\end{array}\right] .
\end{gathered}
$$

So that

$$
\nu_{12}=\frac{-\varepsilon_{2}}{\varepsilon_{1}},
$$

and

$$
\nu_{13}=\frac{-\varepsilon_{3}}{\varepsilon_{1}},
$$

By the symmetry of $c$, we have

$$
\nu_{i j} / E_{i}=\nu_{j i} / E_{j} .
$$

So there are three independent values of Poisson's ratio. We can take these to be

$$
\nu_{12}, \nu_{13}, \nu_{23},
$$

or

$$
\nu_{21}, \nu_{31}, \nu_{32}
$$


For the case of poled piezoelectric ceramics poled in the 3 direction, the best choice is

$$
\nu_{21}, \nu_{31}, \nu_{32}
$$

It is clear that in that case

$$
\nu_{31}=\nu_{32},
$$

so that there are only two independent poisson ratio's, which we may take as

$$
\nu_{21}, \nu_{31} \text {. }
$$

Also we see that $\nu_{31}$ is the poisson ratio stated for piezoceramics and is said to be about

$$
.31
$$

If the engineering strain vector is used then the shear strains are twice the physics shear strains, so that the 2 multiplying a shear modulus is suppressed. The engineering shear strain is equal to the shear angle, the physics shear strain is equal to one half the angle.

The notation for shear modulus $\mu_{i j}$ depends upon which of the index mappings $f$ or $g$ is used in assigning the stress-strain tensor indices to the vector indices.

\subsection{Poling and Piezoelectric Ceramics}

See:

Newnham R E, Trolier-McKinstry S,Giniewicz J R

Piezoelectric, Pyroelectric and Ferroic Crystals

J. Material Education, 15, 189-223 (1993),

(reprint: Penn State MRL annual report to ONR 1994, Appendix 1)

For the nature of the strain vs electric field curve, the nature of domains in PZT, and the morphotropic phase boundary between tetragonal PbTiO3 and rhombohedral PbZrO3 ferroelectric phases, see:

Subbarao E C, Srikanth V, Cao W, Cross L E

Domain Switching And Microcracking During

Poling of Lead Zirconate Titonate Ceramics 
Ferroelectrics 1993 V 145 pp. 271-281

(reprinted: Materials For

Adaptive Structural Acoustic Control, Office

Of Navel Research, Penn State Materials

Research Laboratory, L. Eric Cross ed, V1 1994, appendix 15).

The morphrotropic phase boundary is the boundary between two different structures of the piezoelectric material. We note that "morph" is a root meaning form, and "trop" is a root meaning to turn or change. Hence morphotropic means: a change in form.

Consider the equation

$$
P_{i}=d_{i j} \sigma_{j}
$$

Let the poling direction be the $z$ axis. Then the domains will be randomly directed in the $x y$ plane. Hence the ceramic will be orthotropic relative to the $x y$ plane. Because of this symmetry, the piezoelectric matrix takes the form (see Jaffe, Cook, Jaffe Piezoelectric Ceramics, p20)

$$
\begin{aligned}
d & =\left[\begin{array}{cccccc}
0 & 0 & 0 & 0 & d_{15} & 0 \\
0 & 0 & 0 & d_{24} & 0 & 0 \\
d_{31} & d_{32} & d_{33} & 0 & 0 & 0
\end{array}\right] \\
& =\left[\begin{array}{cccccc}
0 & 0 & 0 & 0 & d_{15} & 0 \\
0 & 0 & 0 & d_{15} & 0 & 0 \\
d_{31} & d_{31} & d_{33} & 0 & 0 & 0
\end{array}\right]
\end{aligned}
$$

The elasticity tensor takes the form

$$
c=\left[\begin{array}{cccccc}
c_{11} & c_{12} & c_{13} & 0 & 0 & 0 \\
c_{12} & c_{22} & c_{13} & 0 & 0 & 0 \\
c_{13} & c_{13} & c_{33} & 0 & 0 & 0 \\
0 & 0 & 0 & c_{44} & 0 & 0 \\
0 & 0 & 0 & 0 & c_{44} & 0 \\
0 & 0 & 0 & 0 & 0 & 2\left(c_{11}-c_{12}\right)
\end{array}\right]
$$

The dielectric tensor is

$$
\left[\begin{array}{ccc}
K_{1} & 0 & 0 \\
0 & K_{1} & 0 \\
0 & 0 & K_{3}
\end{array}\right]
$$


Suppose we have $d_{31}=d_{32}, d_{33}, d_{15}=d_{24}$, and $d_{i j}=0$, otherwise. Then we have

$$
\begin{gathered}
d_{311}=d_{31}, \\
d_{322}=d_{32}, \\
d_{333}=d_{33}, \\
d_{113}=d_{15} / 2, \\
d_{131}=d_{15} / 2, \\
d_{223}=d_{24} / 2, \\
d_{232}=d_{24} / 2,
\end{gathered}
$$

and $d_{i j k}=0$ otherwise.

\subsection{The Equality of Direct and Converse Piezo Coefficients}

This equality may be shown by applying the first and second law's of thermodynamics. Let the stress coefficients $\sigma_{i j}$, the electric field components $E_{i}$ and the temperature $T$ be the state variables. Then write differential expressions for the strain $d e_{i j}$, the electric displacement $d D_{i}$, and the entropy $d S$. Write the internal energy change as

$$
d U=\sigma_{i j} d e_{i j}+E_{i} d D_{i}+T d S .
$$

Introduce the function

$$
\Phi=U-\sigma_{i j} e_{i j}-E_{i} D_{i}-T S .
$$

Compute the differential of $\Phi$ using the last two equations, and also write it in the general partial derivative form. Then equate the partial derivatives to coefficients of the equations. For example

$$
\frac{\partial \Phi}{\partial E_{i}}=-D_{i}
$$

Differentiate to equate derivatives of $e_{i j}, D_{i}$, or $S$ to second order partial derivatives of $\Phi$. This shows for example that the coefficients in the direct piezoelectric effect are equal to the coefficients of the converse piezoelectric effect. See Nye p179. 


\subsection{Typical Values of Piezoelectric Param- eters}

Dielectric constant

$$
\begin{gathered}
K=200=\frac{\epsilon}{\epsilon_{0}} \\
\epsilon_{0}=8.85 \times 10^{-12} \mathrm{farad} / \mathrm{meter} .
\end{gathered}
$$

$K^{T}$ dielectric constant at constant stress. $K^{S}$ dielectric constant at zero strain (constrained piezoelectric coefficient)

$$
\begin{aligned}
& d_{33}=200 \times 10^{-12} \text { coulomb } / \text { newton (or meter } / \text { volt) } \\
& d_{31}=-100 \times 10^{-12} \text { coulomb } / \text { newton (or meter } / \text { volt) } . \\
& d_{15}=400 \times 10^{-12} \text { coulomb } / \text { newton (or meter } / \text { volt) }
\end{aligned}
$$

$g_{i j}$ voltage coefficients.

$$
k_{i j}=\epsilon g_{i j}
$$

Poisson's ratio is approximately .31 for all ceramics. Curie temperature

$$
T_{c}=300 \text {. }
$$

$f_{r}=$ resonant frequency. Typical value is $70 \mathrm{kHz}$.

Panasonic motor.

Operating voltage 22 volts.

Rated output 1 watt.

Torque 250 gf.cm (gf gram force)

$250 \mathrm{gf} \mathrm{cm}$ (pound $/ 454 \mathrm{gf})($ inch $/ 2.54 \mathrm{~cm})(16$ ounce $/$ pound $)=3.47$ inch.ounce

Current . $4 \mathrm{amp}$ at 5 to 10 volts

Input power 2 to 4 watts

Voltage of control circuit 12 volts

250 g.cm $(\mathrm{kg} / 1000 \mathrm{~g})(9.8 \mathrm{~m} / \mathrm{s.s})(\mathrm{m} / 100 \mathrm{~cm})=.0245 \mathrm{~N} . \mathrm{m}$

Angular velocity $=4002 \pi /(\min )(\mathrm{min} / 60 \mathrm{sec})=10.47(1 / \mathrm{s})$

Power $=(.0245)(10.47)=.2565$ watt

Speed $400 \mathrm{rpm}$, noload $600 \mathrm{rpm}$.

$f_{a}=$ antiresonant frequency (parallel resonance)

Electromagnetic coupling constant

$k=$ (electrical energy stored $) /($ mechanical energy stored). 
$k_{p}=.2$ to $.8=$ planar coupling factor of a thin disk.

$Q_{m}=$ quality factor.

Example: Thickness

$$
\begin{gathered}
l=.030 \text { inches }=7.63 \times 10^{-4} \mathrm{~m} \\
v=400 \mathrm{volts} . \\
E=v / l=3.67 \times 10^{6} v / \mathrm{m} . \\
e=d E=\left(200 \times 10^{-12}\right)\left(3.67 \times 10^{6}\right)=7.34 \times 10^{-4} . \\
\Delta z=e l=22 \mu \text { inches }
\end{gathered}
$$

\subsection{Piezoelectric Current and Impedance From A Finite Element Calculation}

Let $D$ be the electric displacement and $\rho$ the charge density. We can use one of Maxwell's equations

$$
\nabla \cdot D=\rho
$$

to show that the surface charge density on a conductor equals the normal component $D_{n}$ of $D$ outside of the conductor. We enclose a conducting surface with a thin pillbox of area $A$, volume $V$, and thickness $\Delta t$. The charge contained in the volume is $A \tau$ where $\tau$ is the surface charge density. Then letting $\Delta t$ go to zero, we have

$$
A \tau=\int_{V} \rho d V=\int_{V} \nabla \cdot D d V=\int_{\partial V} D \cdot n d s \rightarrow D \cdot n A .
$$

Then the charge density is

$$
\tau=D \cdot n=D_{n}
$$

We compute the nodal strains $\varepsilon_{i j}$ from the nodal displacements $u_{i}$ at a face of an element.

From the finite element nodal potentials $\phi_{n}$, we compute derivatives of the shape functions, and then the gradient of the potential. Then we obtain the electric field $E_{i}$ as the negative gradient of the potential,

$$
E=-\nabla \phi
$$


We compute the electric displacement from the piezoelectric equation

$$
D_{i}=e_{i j k} \varepsilon_{j k}+K_{i j} E_{j} .
$$

Then we compute the normal component $D_{n}$. This gives the surface charge density. Multiplying by the area $A$, we get the charge $q$. We sum up the charges on the boundaries of the elements to get the total electrode charge. If we calculate the charge as a function of time, we can fit it to a function

$$
Q_{0} \cos (\omega t+\psi),
$$

and thus to the real part of the exponential

$$
Q_{0} \exp (j(\omega t+\psi)) .
$$

Differentiating with respect to time we get the current

$$
I=I_{0} \exp (j(\omega t+\psi)) .
$$

Then if $V$ is the applied voltage, the impedance is

$$
Z=V / I .
$$

We can also compute energy storage and dissipation in the finite element model, and relate it to energy storage and dissipation in an equivalent circuit. We can obtain or compute the energy density of the electric field

$$
\frac{D \cdot E}{2},
$$

the elastic strain energy, the kinetic energy, heat dissipation, and frictional contact energy. The kinetic energy will correspond to inductor energy in the equivalent circuit, the strain energy and the electric field energy will correspond to capacitive energy, and the dissipation energy will correspond to a resistance loss. If the energies correspond, then the equivalent circuit is valid. 


\subsection{Piezoelectric Cube Example}

Consider a piezoelectric cube of side $a$. Let thin metal plates be located at $z=0$ and $z=a$. Let there be a voltage $V$ on these plates. Let there be a horizontal compressive forces $F$ in the $y$ direction acting on the $y=0$, and the $y=a$ faces of the block. The electric field is

$$
E=\left[\begin{array}{c}
E_{1} \\
E_{2} \\
E_{3}
\end{array}\right]=\left[\begin{array}{c}
0 \\
0 \\
V / a
\end{array}\right]
$$

The stress is

$$
\sigma=\left[\begin{array}{c}
\sigma_{1} \\
\sigma_{2} \\
\sigma_{3} \\
\sigma_{4} \\
\sigma_{5} \\
\sigma_{6}
\end{array}\right]=\left[\begin{array}{c}
F / a^{2} \\
0 \\
0 \\
0 \\
0 \\
0
\end{array}\right]
$$

An average dielectric constant for PZT is

$$
K=200=\frac{\epsilon}{\epsilon_{o}}=1+\chi .
$$

We have

$$
\epsilon_{0}=8.85 \times 10^{10}\left(C^{2} / N M^{2}\right) .
$$

Then the permittivity is

$$
\epsilon=1.77 \times 10^{-9} .
$$

If we take the material to be isotropic, the polarization equation becomes

$$
P=\epsilon_{0} \chi E+\left[\begin{array}{cccccc}
0 & 0 & 0 & 0 & d_{15} & 0 \\
0 & 0 & 0 & 0 & d_{25} & 0 \\
d_{31} & d_{32} & d_{33} & 0 & 0 & 0
\end{array}\right]\left[\begin{array}{c}
\sigma_{1} \\
\sigma_{2} \\
\sigma_{3} \\
\sigma_{4} \\
\sigma_{5} \\
\sigma_{6}
\end{array}\right]
$$

We have

$$
d_{31}=d_{32}=-100 \times 10^{-12} \mathrm{C} / \mathrm{N} \text { or } \mathrm{M} / \mathrm{V}
$$




$$
\begin{gathered}
d_{33}=2100 \times 10^{-12} \\
d_{51}=d_{15}=400 \times 10^{-12}
\end{gathered}
$$

Because only $\sigma_{1}$ is nonzero, we have

$$
P=\epsilon_{0} \chi E+\left[\begin{array}{c}
0 \\
0 \\
d_{31} \sigma_{1}
\end{array}\right]
$$

Then

$$
\begin{gathered}
P_{3}=\epsilon_{0} \chi E_{3}+d_{31} \sigma_{1} \\
D=\epsilon_{0} E+P . \\
D_{3}=\epsilon_{0}(1+\chi) E_{3}+d_{31} \sigma_{1}=\epsilon_{0} K E_{3}+d_{31} \sigma_{1} .
\end{gathered}
$$

The surface charge on the $z=a$ face is

$$
Q=D_{3} a^{2}
$$

The strain is

$$
e=\left[\begin{array}{ccc}
0 & 0 & d_{31} \\
0 & 0 & d_{32} \\
0 & 0 & d_{33} \\
0 & d_{25} & 0 \\
d_{15} & 0 & 0 \\
0 & 0 & 0
\end{array}\right]\left[\begin{array}{l}
E_{1} \\
E_{2} \\
E_{3}
\end{array}\right]+\left[\begin{array}{cccccc}
c_{11} & c_{12} & c_{13} & 0 & 0 & 0 \\
c_{21} & c_{22} & c_{33} & 0 & 0 & 0 \\
c_{31} & c_{32} & c_{33} & 0 & 0 & 0 \\
0 & 0 & 0 & c_{44} & 0 & 0 \\
0 & 0 & 0 & 0 & c_{55} & 0 \\
0 & 0 & 0 & 0 & 0 & c_{66}
\end{array}\right]\left[\begin{array}{l}
\sigma_{1} \\
\sigma_{2} \\
\sigma_{3} \\
\sigma_{4} \\
\sigma_{5} \\
\sigma_{6}
\end{array}\right]
$$

So the nonzero elements of the strain are

$$
\begin{aligned}
& e_{1}=d_{31} E_{3}+\sigma_{1} c_{11}=d_{31} E_{3}+\frac{\sigma_{1}}{\xi} \\
& e_{2}=d_{32} E_{3}+\sigma_{1} c_{21}=d_{32} E_{3}-\frac{\sigma_{1} \nu}{\xi}, \\
& e_{3}=d_{33} E_{3}+\sigma_{1} c_{31}=d_{33} E_{3}-\frac{\sigma_{1} \nu}{\xi},
\end{aligned}
$$

where $\xi$ is Young's modulus, and $\nu$ is Poisson's ratio. 


\subsection{Generating Ferroelectric Hysteresis Curves}

Suppose we arrange two capacitors in series, one $C_{1}$ containing a ferroelectric dielectric, and the second $C_{2}$ a nonferroelectric dielectric. Let us connect in series an alternating high voltage source. Let $V_{1}$ be the voltage across capacitor $C_{1}$. This is a measure of the $E$ field in the ferroelectric capacitor $C_{1}$. The charge on the plates of $C_{1}$ is proportional to the $D$ field (actually the $D$ field is equal to the surface charge density). But the charge on $C_{1}$ is equal to the charge on $C_{2}$ and moves from $C_{1}$ to $C_{2}$ and back again during a cycle of the applied alternating voltage. But the second capacitor is nonferroelectric and its dielectric is linear, so that the voltage $V_{2}$ across the second capacitor is proportional to charge and hence to the $D$ field of the ferroelectric capacitor. Therefore, if we connect $V_{1}$ across the horizontal plates of an oscilloscope, and $V_{2}$ across the vertical plates, we will see the hysteresis curve. The polarization field will be approximately equal to $D$, since the permittivity $\epsilon$ for the ferroelectric is much larger than the permittivity of free space $\epsilon_{0}$.

(I think this is close to the method given by Sawyer and Tower, see bibliography.)

\subsection{The Strain Hysteresis Curve}

The strain vs electric field curve for a piezoelectric ceramic is a butterfly curve with the strain always of one sign, and the curve lying in the positive upper half plane.

\subsection{Relaxors}

A relaxor ferroelectric has some of the properties of a normal ferroelectric, but is not so permanently polarized and has a very narrow hysteresis loop. When the field is removed, the material almost returns to an unpolarized state. It requires a bias field.

See:

Cross L Eric

Relaxor Ferroelectrics: An Overview

Ferroelectrics, 1994 v151 pp. 305-320 
(reprinted: annual report 1994 from MRL at Penn State to ONR v1 p305)

\subsection{Electrostriction}

Electrostriction is an internal stress caused by the force of the electric field on charges. It occurs in all materials, not just piezoelectric ones. A computation shows it to be related to the gradient of the dielectric constant, and in practice the stress is proportional to the square of the electric field intensity. It is very hard to measure, since the force can be masked by the force due to the free charges on the capacitor plates.

Notes and references to electrostriction: Wert, Thomson Physics of Solids, p. 321. Julius Adams Stratton, Electromagnetic Theory, pp149151. Panofsky and Philips Classical Electricity and Magnetism p.95, As a term of an equation. Maxwell stress tensor. Classical derivation. The treatment in Panofsky and Phillips is based on the treatment in Becker: (formerly called Becker and Abraham) Electromagnetic Fields and Interactions p. 134. In Jaffe: Piezoelectric Ceramics, Electrostriction is mentioned on pages 15 and 78. He relates electrostriction to domain reversal. Jaffe says that the effect is significant only for ferroelectrics above the Curie point. Cady: Piezoelectricity defines electrostriction to be that effect that is proportional to $\|E\|^{2}$. See pages $4,198,199,614$. Cady states that electrostriction is only significant for fields above 20,000 volts per $\mathrm{cm}$. See also Auld, Acoustic Fields and Waves in Solids, volumes I and II, who presents a nice one dimensional model of the piezoelectric effect on p265.

\subsection{The Conversion Program: pzansys.ftn}

This program does the conversion calculations derived in the previous sections. It requires as input the $d$ parameters, and either the elasticity matrix, or its inverse. It computes the $e$ parameters, and computes the clamped permittivity (strain constant) from the unclamped permittivity. It generates material property cards for the ANSYS program. We list the program in a later section. The next sections illustrate the operation of the program. 


\title{
0.18 Example: Parameter Conversion Using Compliance Components
}

\author{
Jonada:/users/u51195 \$ pzansys \\ Roforonco: Jim Emery "Piozoeloctricity", \\ Document location:/u61195/ps/piozoolc.ps,piezoelc.tex \\ Anonymors FTP: Itp.0s.kcp.com /pub/emery/ \\ Units aro motric: Morton, Moter, Kilogram \\ stress: Iovton/I-2 (Pasculs) \\ Young's Hodulus: Pascals \\ BlasticitJ coofficionts: Pascals \\ Enter piezoelectric d constants (coulomb/nerton) \\ The IRs convention for piezoelectric labeling is used \\ Type 〈roturn〉 for default ralue \\ Enter d33 [ 2.0000000000000001E-10] \\ Enter d31 [ -1.0000000000000000E-10] \\ Enter d15 [ 4.00000000000000018-10] \\ d matrix= \\ $\begin{array}{lllllll}0.0000 \mathrm{E}+00 & 0.0000 \mathrm{E}+00 & 0.0000 \mathrm{E}+00 & 0.0000 \mathrm{E}+00 & 0.4000 \mathrm{E}-09 & 0.0000 \mathrm{E}+00\end{array}$ \\ $\begin{array}{lllllll}0.0000 \mathrm{E}+00 & 0.0000 \mathrm{E}+00 & 0.0000 \mathrm{~B}+00 & 0.4000 \mathrm{E}-09 & 0.0000 \mathrm{E}+00 & 0.0000 \mathrm{E}+00\end{array}$ \\ $\begin{array}{lllllll}-0.1000 \mathrm{E}-09 & -0.1000 \mathrm{E}-09 & 0.2000 \mathrm{E}-09 & 0.0000 \mathrm{E}+00 & 0.0000 \mathrm{E}+00 & 0.0000 \mathrm{E}+00\end{array}$ \\ Do Jor vant to see the nonzero components \\ of the $27 \mathrm{~d}$ tensor components? [n] \\ Define the elasticity matrix or compliance matrix: \\ (1)Use olastic constants to define compliance \\ for orthotropic material, using Young's moduli, \\ Poissons ratios, and Shear Hoduli. \\ (2) Use the five components of the olastic matrix \\ c11,c33,c44 (c44 is AlsYS c66), c12,c13, \\ for a z-polod coramic. \\ (Iote: $c 22=c 11, c 55=c 44, c 66=2(c 11-c 12), c 23=c 13$, \\ and $c_{-}\{23\}=c_{-}\{13\}$. Coofficients which are \\ not in the uppor 3-dimensional submatrix, \\ not on tho main diagonal, aro zero. \\ (3) Use the fire components of the compliance matrix \\ s11,s33,s44 ( $s 44$ is AISYS s66), s12,s13, \\ for a z-poled coramic. \\ (Ioto: s22=s11, s55=s44, s66=2(s11-s12), s23=s13, \\ and $s_{-}\{23\}=s_{-}\{13\}$. Coofficients which are \\ not in the upper 3-dimonsional submatrix, \\ not on the main diagonal, ore zero. \\ typo 〈return> for default solection: [1] \\ Bntor the orthotropic elastic constants \\ for a coordinate system in the principle directions \\ Enter Young's Hodulus, in $x[0.12800 \mathrm{E}+12]$
}


Enter Young's Hodulus, in $\mathrm{J}$ [ $0.12800 \mathrm{~B}+12]$

Enter Young's Modulus, in $=[0.11000 \mathrm{E}+12]$

Enter AISYS Poisson ratios (Theory sec. 2.1)

Enter llajor Poisson ratio prxy $[0.30000]$

Enter Hajor Poisson ratio prrz[ 0.41976$]$

Enter Iajor Poisson ratio pryz $[0.41976]$

Enter shear modulus B23 [ $0.52000 E+11]$

Enter shoar modulus g13 [0.52000 +11$]$

Enter shear modulus g12 [0.12200E+12]

Compliance matrix (olasticity invorso) cinv=

$\begin{array}{llllll}0.7813 \mathrm{E}-11 & -0.2344 \mathrm{E}-11 & -0.3279 \mathrm{E}-11 & 0.0000 \mathrm{E}+00 & 0.0000 \mathrm{E}+00 & 0.0000 \mathrm{E}+00\end{array}$

$\begin{array}{llllll}-0.2344 \mathrm{E}-11 & 0.7813 \mathrm{E}-11 & -0.3279 \mathrm{E}-11 & 0.0000 \mathrm{E}+00 & 0.0000 \mathrm{E}+00 & 0.0000 \mathrm{E}+00\end{array}$

$\begin{array}{llllll}-0.3279 \mathrm{E}-11 & -0.3279 \mathrm{E}-11 & 0.9091 \mathrm{E}-11 & 0.0000 \mathrm{E}+00 & 0.0000 \mathrm{E}+00 & 0.0000 \mathrm{E}+00\end{array}$

$\begin{array}{lllllll}0.0000 \mathrm{E}+00 & 0.0000 \mathrm{E}+00 & 0.0000 \mathrm{E}+00 & 0.1923 \mathrm{E}-10 & 0.0000 \mathrm{E}+00 & 0.0000 \mathrm{E}+00\end{array}$

$\begin{array}{lllllll}0.0000 \mathrm{E}+00 & 0.0000 \mathrm{E}+00 \cdot 0.0000 \mathrm{E}+00 & 0.0000 \mathrm{E}+00 & 0.1923 \mathrm{E}-10 & 0.0000 \mathrm{E}+00\end{array}$

$\begin{array}{lllllll}0.0000 \mathrm{E}+00 & 0.0000 \mathrm{E}+00 & 0.0000 \mathrm{E}+00 & 0.0000 \mathrm{E}+00 & 0.0000 \mathrm{E}+00 & 0.8197 \mathrm{E}-11\end{array}$

lote: In AISYS components $4,6,6$ are permuted

(A difforent mapping from tensor to vector is used):

AIISYS 44 is 68

AIISYS 55 is 44

AIISYS 66 is 55

The five indepondent compliance coeficients aro:

$s 11=0.78125000 \mathrm{E}-11$

$s 33=0.90909091 \mathrm{E}-11$

$s 44=0.19230769 \mathrm{~B}-10$

$s 12=-0.23437500 \mathrm{~B}-11$

$s 13=-0.32793388 \mathrm{E}-11$

Computing inverse matrix

Elasticity matrix $=$

$\begin{array}{llllll}0.2104 \mathrm{E}+12 & 0.1119 \mathrm{E}+12 & 0.1163 \mathrm{E}+12 & 0.0000 \mathrm{E}+00 & 0.0000 \mathrm{E}+00 & 0.0000 \mathrm{E}+00\end{array}$

$\begin{array}{llllll}0.1119 \mathrm{E}+12 & 0.2104 \mathrm{E}+12 & 0.1163 \mathrm{E}+12 & 0.0000 \mathrm{E}+00 & 0.0000 \mathrm{E}+00 & 0.0000 \mathrm{E}+00\end{array}$

$\begin{array}{llllll}0.1163 \mathrm{E}+12 & 0.1163 \mathrm{E}+12 & 0.1939 \mathrm{E}+12 & 0.0000 \mathrm{E}+00 & 0.0000 \mathrm{E}+00 & 0.0000 \mathrm{E}+00\end{array}$

$\begin{array}{lllllll}0.0000 \mathrm{E}+00 & 0.0000 \mathrm{E}+00 & 0.0000 \mathrm{E}+00 & 0.5200 \mathrm{E}+11 & 0.0000 \mathrm{E}+00 & 0.0000 \mathrm{E}+00\end{array}$

$\begin{array}{lllllll}0.0000 \mathrm{E}+00 & 0.0000 \mathrm{E}+00 & 0.0000 \mathrm{E}+00 & 0.0000 \mathrm{E}+00 & 0.5200 \mathrm{E}+11 & 0.0000 \mathrm{E}+00\end{array}$

$\begin{array}{lllllll}0.0000 \mathrm{E}+00 & 0.0000 \mathrm{E}+00 & 0.0000 \mathrm{E}+00 & 0.0000 \mathrm{E}+00 & 0.0000 \mathrm{E}+00 & 0.1220 \mathrm{E}+12\end{array}$

Orthotropic constants from compliance matrix:

Young's Hodulus $1=0.12800000 \mathrm{~B}+12$

Young's Yodulus $2=0.12800000 \mathrm{~B}+12$

Young's Hodulus $3=0.11000000 \mathrm{~B}+12$

Hajor Poisson ratio prxy $=0.30000000$

Irajor Poisson ratio prxz= 0.41975537

Kajor Poisson ratio pryz $=0.41975637$

Shoar Hodulus g23 $=0.52000000 \mathrm{E}+11$

Shour Mlodulus g13 $=0.52000000 E+11$

Shear Modulus $8^{12}=0.12200000 E+12$ 


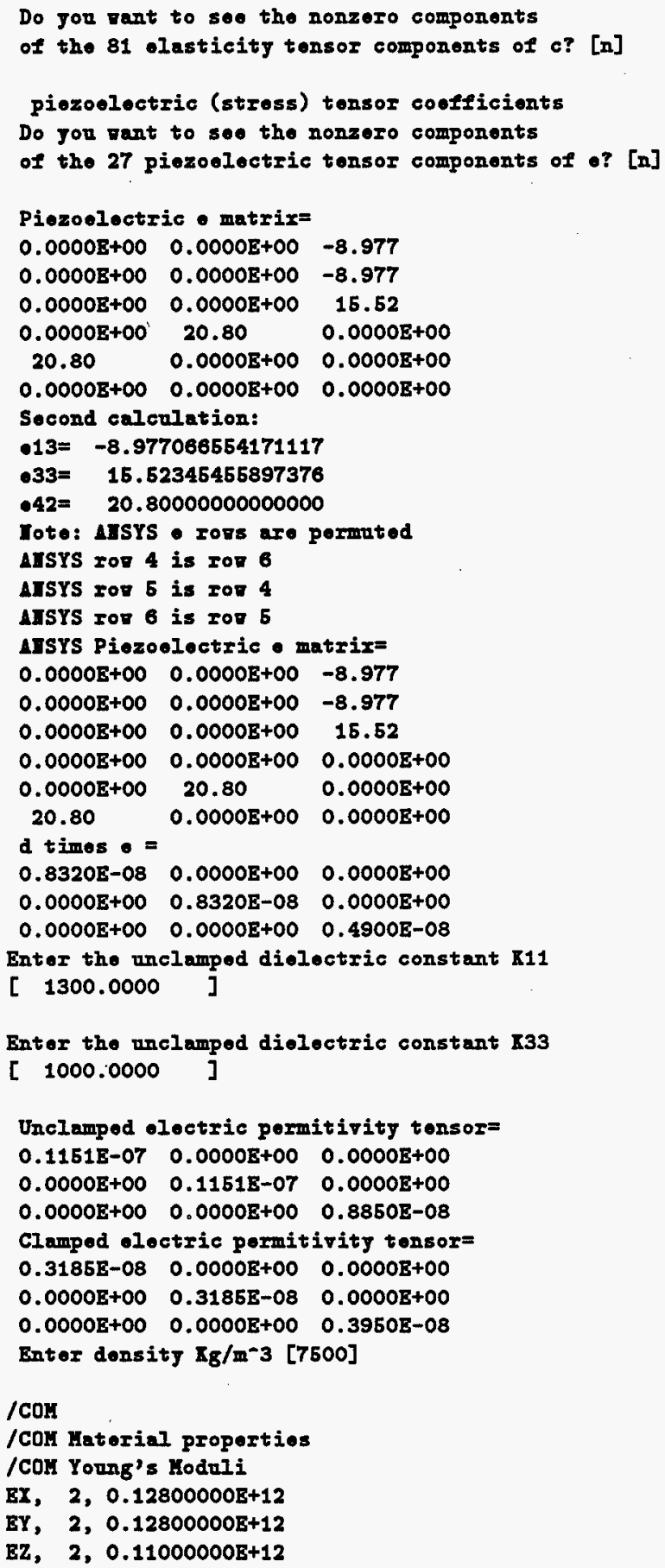

$/ \mathrm{COH}$

/COM Haterial properties

/COM Young's Hoduli

EX, $2,0.12800000 \mathrm{E}+12$

EY, $2,0.12800000 \mathrm{E}+12$

$\mathrm{EZ}, 2,0.11000000 \mathrm{E}+12$ 
/COK AISYS "Hajor" Poisson retios

PRXY, 2, 0.30000000

PRXZ, 2, 0.41975537

PRYZ, 2, 0.41975537

/COH Density $\mathrm{K}_{\mathrm{g}} / \mathrm{m}^{-3}$

/COH DEIS, 2, 0.75000000E-02

/COH clamped Permitivitios

IFP, PERX, 2, 0.31850000E-08

ILP, PERY, 2, 0.31850000E-08

KIP, PERZ, 2, $0.39498958 E-08$

/COH ArsYS Piezoolectric "ه" matrix

TB, PIEZ, 3

TBDATA, 3, -8.9770666

TBDATA, 6, -8.9770666

TBDATA, $9,15.523455$

TBDATA, 14, 20.800000

TBDATA, 16, 20.800000

\subsection{Example: Parameter Conversion Us- ing Four Independent Elasticity Com- ponents}

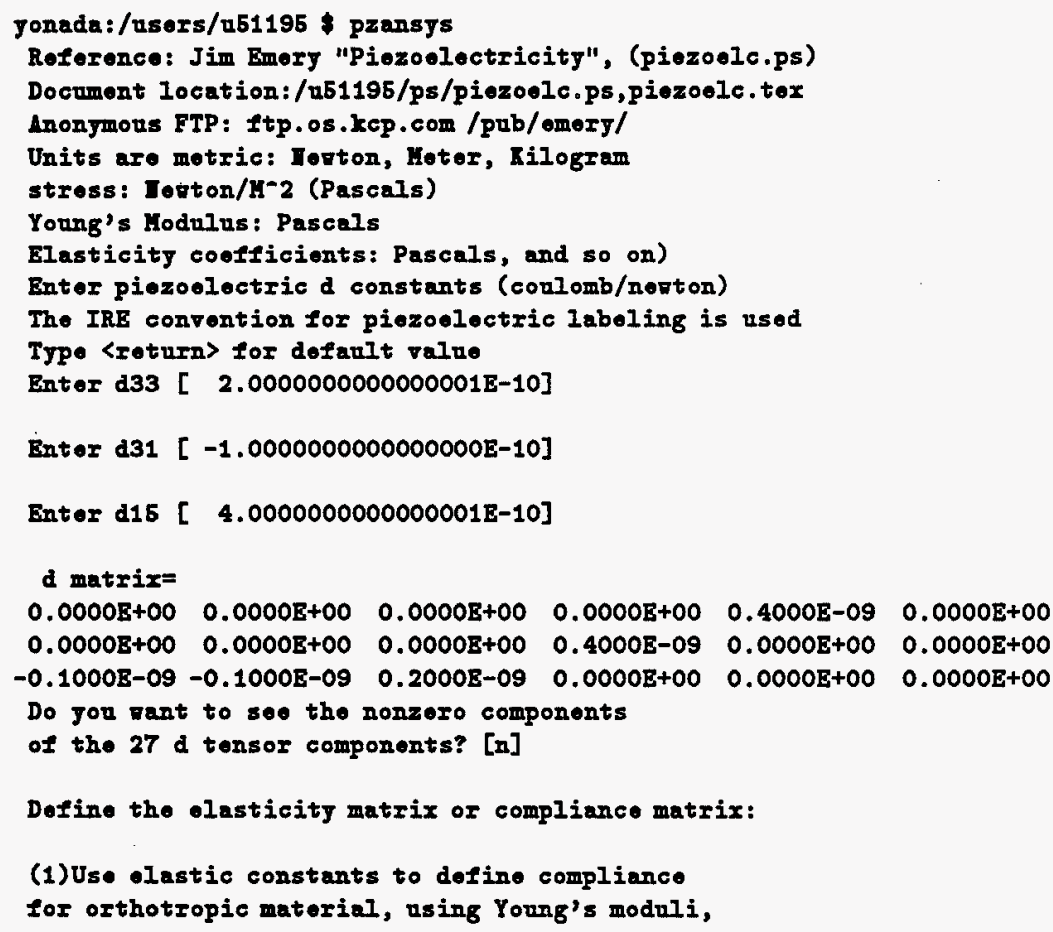


Poissons ratios, and Shoar Moduli.

(2) Use the Iive components of the elastic matrix c11,c33,c44 (c44 is AISYS c66),c12,c13, for a z-poled ceramic. (Iote: $c 22=c 11, c 55=c 44, c 66=2(c 11-c 12), c 23=c 13$, and $c_{-}\{23\}=c_{-}\{13\}$. Coefficients which aro not in the upper 3-dimensionel submatrix, not on the main diagonal, are zero.

(3) Use the five components of the compliance matrix $s 11, s 33, s 44$ ( $s 44$ is AISYS $s 66$ ), s12,s13,

for a z-poled ceramic.

(Wote: $s 22=s 11, s 55=s 44, s 66=2(s 11-s 12), s 23=s 13$, and $s_{-}\{23\}=s_{-}\{13\}$. Cooficients which aro not in the upper 3-dimensional submatrix, not on the main diagonal, are zero.

type 〈return〉 for defanlt selection: [1] 2

Enter e11 [ $0.13200 \mathrm{E}+12]$

Enter 033 [ $0.11500 \mathrm{E}+12]$

Enter c44 (AISYS c66) [ $0.52000 E+11]$

Enter c12 [ $0.71000 \mathrm{E}+11]$

Enter c13 [0.73000E+11]

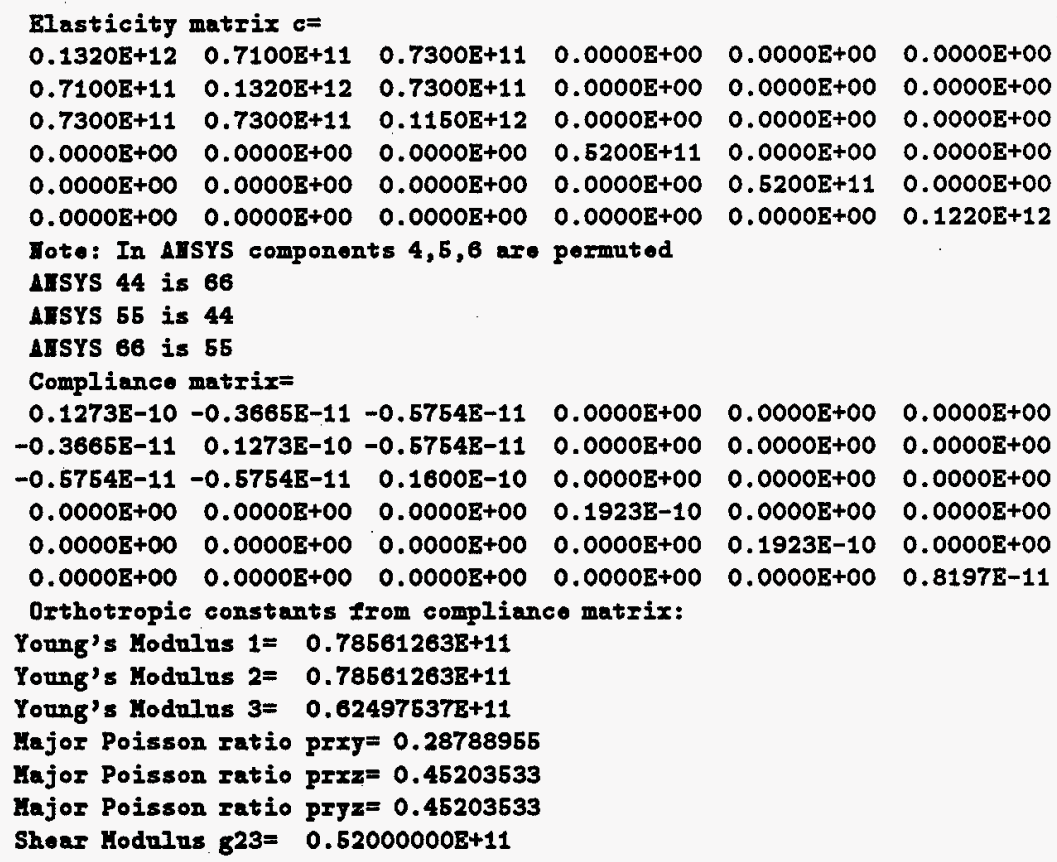




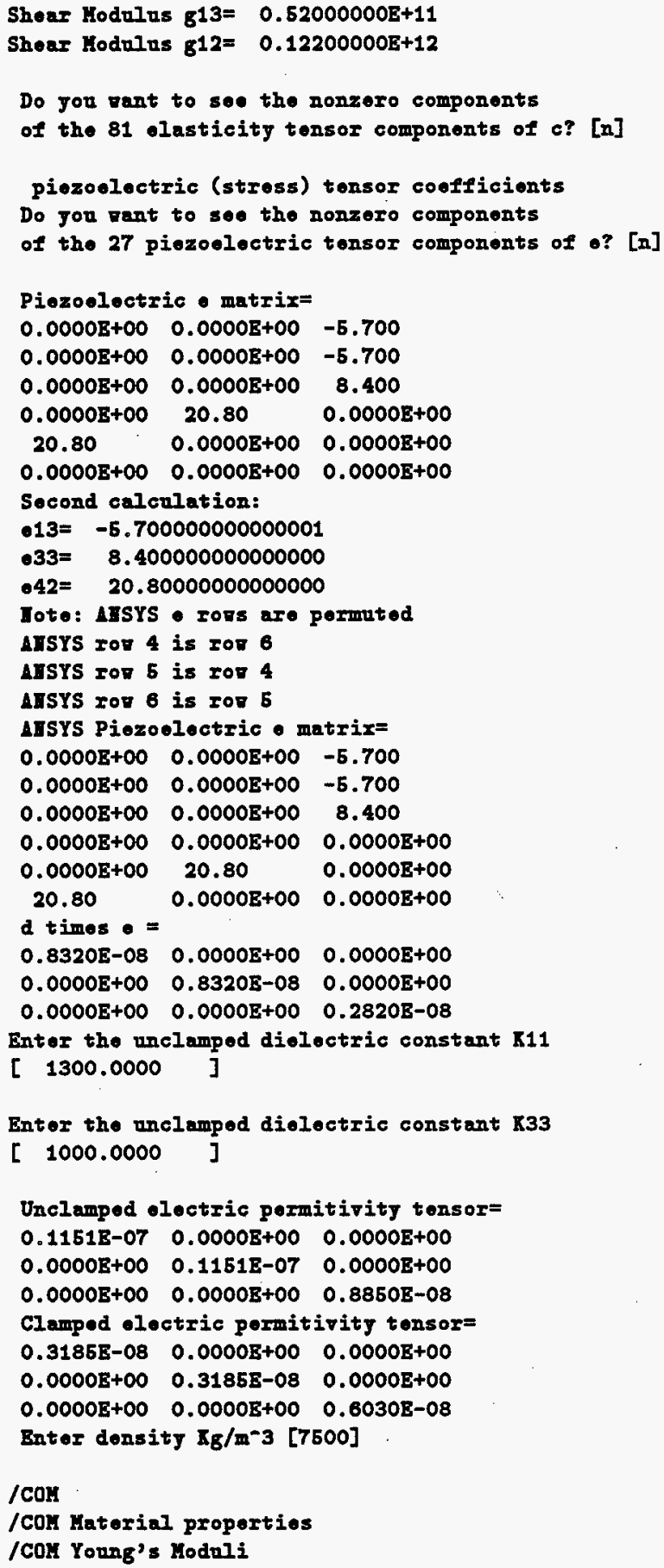


EX, 2, $0.78561263 \mathrm{E}+11$

EY, 2, $0.78561263 E+11$

EZ, 2, $0.62497537 \mathrm{E}+11$

/COY AISYS "Hajor" Poisson ratios

PRIY, 2, 0.28788955

PRIZ, 2, 0.45203533

PRYZ, 2, 0.45203533

/COH Donsity $\mathrm{Xg} / \mathrm{m}^{-3}$

/COH DEIS, 2, 0.75000000E-02

/COH clamped Permitivities

IP, PERI, 2, $0.31850000 \mathrm{E}-08$

YIP, PERY, $2,0.31850000 \mathrm{E}-08$

IP, PERZ, 2, 0.60300000E-08

/COY ArSYS Piezooloctric "o" matrix

TB, PIEZ, 3

TBDATA, 3, -5.7000000

TBDATL, 6, -5.7000000

TBDATA, 9, 8.4000000

TBDATA, 14, 20.800000

TBDATA, 16, 20.800000

\title{
0.20 Example, Orthotropic Elastic Constants
}

\author{
ReIerence: Jim Bmery "Piezoelectricity", (piezoele.ps) \\ Document location:/u51195/ps/piezoelc.ps,piezoelc.tex \\ Anonymous FTP: Itp.os.kcp.com /pub/omery/ \\ Units aro motric: Bonton, Hoter, Kilogram \\ stress: Iorton/11ศ2 (Pascals) \\ Young's Modulus: Pascals \\ Elasticity coofficients: Pascals, and so on) \\ Enter piezooloctric d constants (coulomb/norton) \\ The IRE convention for piezoeloctric labeling is used \\ Type 〈roturn〉 for dofault value \\ Enter d33 [ 2.0000000000000001E-10] \\ Enter d31 $[-1.0000000000000000 \mathrm{E}-10]$ \\ Enter d15 [ 4.0000000000000001E-10] \\ d matrix= \\ $\begin{array}{lllllll}0.0000 \mathrm{E}+00 & 0.0000 \mathrm{E}+00 & 0.0000 \mathrm{E}+00 & 0.0000 \mathrm{E}+00 & 0.4000 \mathrm{E}-09 & 0.0000 \mathrm{E}+00\end{array}$ \\ $\begin{array}{lllllll}0.0000 \mathrm{E}+00 & 0.0000 \mathrm{E}+00 & 0.0000 \mathrm{E}+00 & 0.4000 \mathrm{E}-09 & 0.0000 \mathrm{E}+00 & 0.0000 \mathrm{E}+00\end{array}$ \\ $\begin{array}{lllllll}-0.1000 \mathrm{E}-09 & -0.1000 \mathrm{E}-09 & 0.2000 \mathrm{E}-09 & 0.0000 \mathrm{E}+00 & 0.0000 \mathrm{E}+00 & 0.0000 \mathrm{E}+00\end{array}$ \\ Do you rant to soe the nonzero components \\ of the 27 a tonsor components? [n] \\ Define the elasticity matrix or compliance matrix: \\ (1) Use elastic constants to define compliance \\ for orthotropic materiel, using Young's moduli, \\ Poissons ratios, and Shoar Hoduli. \\ (2)Use the five components of the elastic matrix \\ $c 11, c 33, c 44$ (c44 is AISYS c66), c12,c13, \\ for a z-poled coramic. \\ (Ioto: $c 22=c 11, c 55=c 44, c 68=2(c 11-c 12), c 23=c 13$, \\ and $c_{-}\{23\}=c_{-}\{13\}$. Coofficients ghich aro
}


not in the upper 3-dimensional submatrix, not on the main diagonal, axe zoro.

(3)Use the fire components of the compliance matrix $811,833,844$ ( 844 is LISYS 566 ), s12,s13, Ior a zoled ceramic.

(Iot•: $s 22=s 11, s 55=s 44, s 66=2(s 11-s 12), s 23=s 13$, and $s_{-}\{23\}=s_{-}\{13\}$. Coofficients which aro not in the upper 3-dimensionel submatrix, not on tho main diagonal, are zero.

type 〈return〉 for default soloction: [1] Enter the orthotropic elastic constants for a coordinate system in the principle directions Enter Young's Hodulus, in $x$ [ 0.12800E+12] Enter Young's Hodulns, in $J[0.12800 \mathrm{~B}+12]$ Enter Young's Modulus, in $z$ [0.11000E+12]

Entor AISYS Poisson ratios (Thoory sec. 2.1) Enter Hajor Poisson ratio prxy [ 0.30000 Enter Hajor Poisson ratio prrz $[0.41976$ Enter Hajor Poisson ratio prya[ 0.41976 Bnter shear modulus B23 [ $0.52000 \mathrm{~B}+11]$ Enter shour modulus g13 [ $0.52000 \mathrm{E}+11]$ Enter shear modulns $\mathrm{B}^{12}$ [ $\left.0.12200 \mathrm{E}+12\right]$ Complinnce matrix (elasticity inverso) cinv=

$\begin{array}{llllll}0.7813 \mathrm{E}-11 & -0.2344 \mathrm{E}-11 & -0.3279 \mathrm{E}-11 & 0.0000 \mathrm{E}+00 & 0.0000 \mathrm{E}+00 & 0.0000 \mathrm{E}+00\end{array}$ $\begin{array}{llllll}-0.2344 \mathrm{E}-11 & 0.7813 \mathrm{E}-11 & -0.3279 \mathrm{E}-11 & 0.0000 \mathrm{E}+00 & 0.0000 \mathrm{E}+00 & 0.0000 \mathrm{E}+00\end{array}$ $\begin{array}{llllll}-0.3279 \mathrm{E}-11 & -0.3279 \mathrm{~B}-11 & 0.9091 \mathrm{E}-11 & 0.0000 \mathrm{E}+00 & 0.0000 \mathrm{E}+00 & 0.0000 \mathrm{E}+00\end{array}$ $\begin{array}{lllllll}0.0000 E+00 & 0.0000 E+00 & 0.0000 E+00 & 0.1923 E-10 & 0.0000 E+00 & 0.0000 E+00\end{array}$ $\begin{array}{lllllll}0.0000 \mathrm{E}+00 & 0.0000 \mathrm{E}+00 & 0.0000 \mathrm{E}+00 & 0.0000 \mathrm{E}+00 & 0.1923 \mathrm{E}-10 & 0.0000 \mathrm{E}+00\end{array}$ $\begin{array}{lllllll}0.0000 E+00 & 0.0000 E+00 & 0.0000 E+00 & 0.0000 E+00 & 0.0000 E+00 & 0.8197 E-11\end{array}$ Iote: In AISYS components $4,5,6$ are permuted

(A different mapping from tensor to vector is used): AISYS 44 is 66

AISYS 55 is 44 AISYS 66 is 55

The fire independent compliance coeficients are:

$s 11=0.78125000 \mathrm{E}-11$

$s 33=0.90909091 \mathrm{E}-11$

$s 44=0.19230769 \mathrm{E}-10$

$s 12=-0.23437500 \mathrm{E}-11$

$s 13=-0.32793388 \mathrm{E}-11$

Computing inverse matrix

Elasticity matrix =

$\begin{array}{llllll}0.2104 \mathrm{E}+12 & 0.1119 \mathrm{E}+12 & 0.1163 \mathrm{E}+12 & 0.0000 \mathrm{E}+00 & 0.0000 \mathrm{E}+00 & 0.0000 \mathrm{E}+00\end{array}$

$\begin{array}{llllll}0.1119 \mathrm{E}+12 & 0.2104 \mathrm{E}+12 & 0.1163 \mathrm{E}+12 & 0.0000 \mathrm{E}+00 & 0.0000 \mathrm{E}+00 & 0.0000 \mathrm{E}+00\end{array}$

$\begin{array}{lllllll}0.1163 E+12 & 0.1163 E+12 & 0.1939 E+12 & 0.0000 E+00 & 0.0000 E+00 & 0.0000 E+00\end{array}$

$\begin{array}{lllllll}0.0000 \mathrm{E}+00 & 0.0000 \mathrm{E}+00 & 0.0000 \mathrm{E}+00 & 0.6200 \mathrm{E}+11 & 0.0000 \mathrm{E}+00 & 0.0000 \mathrm{E}+00\end{array}$

$\begin{array}{lllllll}0.0000 \mathrm{E}+00 & 0.0000 \mathrm{E}+00 & 0.0000 \mathrm{E}+00 & 0.0000 \mathrm{E}+00 & 0.5200 \mathrm{E}+11 & 0.0000 \mathrm{E}+00\end{array}$

$\begin{array}{lllllll}0.0000 \mathrm{E}+00 & 0.0000 \mathrm{E}+00 & 0.0000 \mathrm{E}+00 & 0.0000 \mathrm{E}+00 & 0.0000 \mathrm{E}+00 & 0.1220 \mathrm{E}+12\end{array}$

Orthotropic constants from compliance matrix:

Young's Hodulus $1=0.12800000 E+12$

Young's Modulus $2=0.12800000 \mathrm{E}+12$

Young's Yodulus $3=0.11000000 \mathrm{E}+12$

rajor Poisson ratio prxy $=0.30000000$ 
Hajor Poisson ratio prxz $=0.41975637$

Hajor Poisson ratio pryz $=0.41975637$

Shear Hodulus $g^{23}=0.52000000 E+11$

Shoar Hodulus $\mathrm{g}^{13}=0.52000000 \mathrm{~B}+11$

Shear Hodnlus $\mathbf{g}^{12}=0.12200000 \mathrm{E}+12$

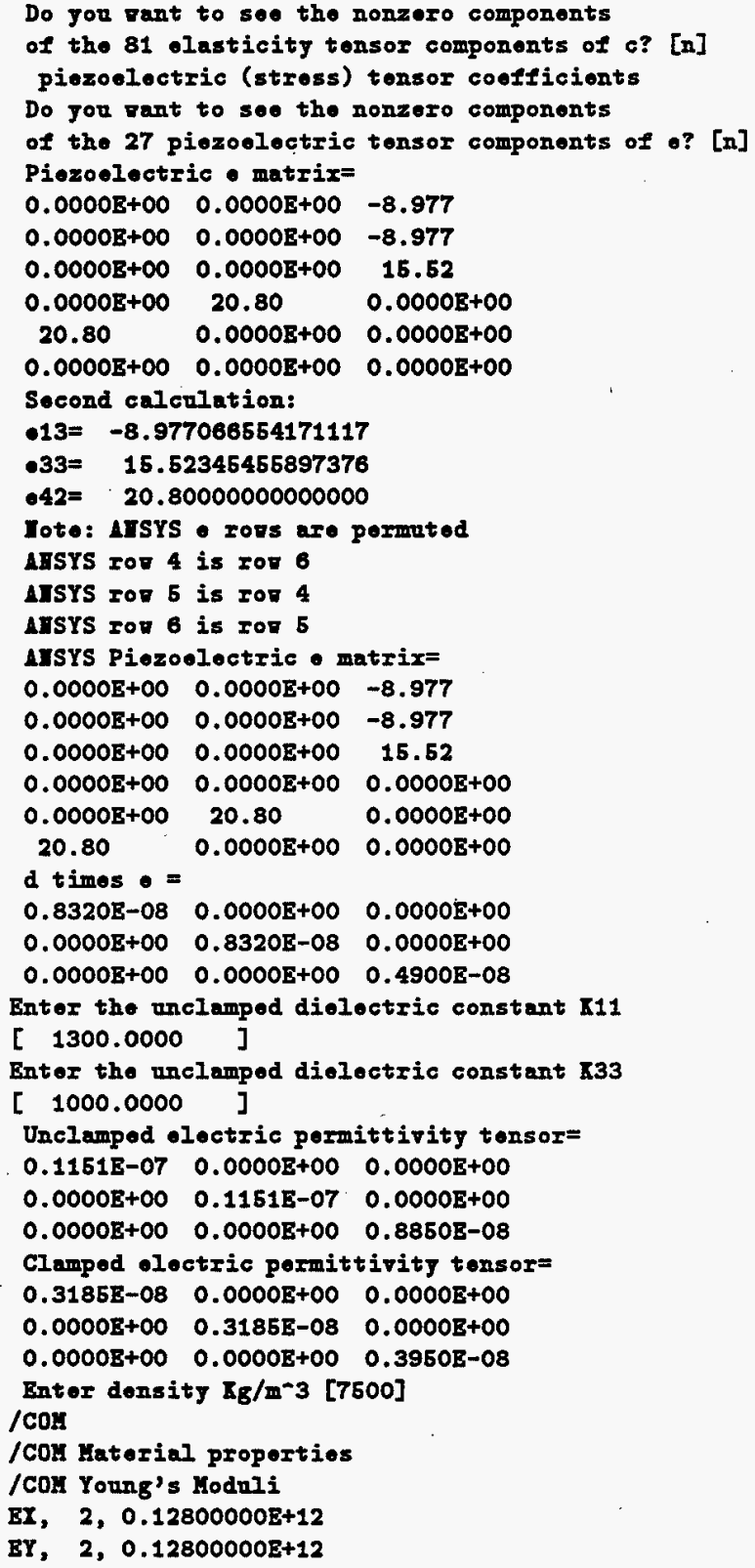


BZ, 2, $0.11000000 \mathrm{R}+12$

/COH AISYS "Hajor" Poisson ratios

PRXY, 2, 0.30000000

PRXZ, 2, 0.41975537

PRYZ, 2, 0.41975537

/COH Density $\mathrm{Kg} / \mathrm{m}^{-3}$

/COH DEIS, 2, 0.75000000E-02

/COY clamped Permitivities

KP, PERX, 2, 0.31850000E-08

IIP, PERY, $2,0.31850000 \mathrm{E}-08$

KP, PERZ, 2, $0.39498958 \mathrm{E}-08$

/COH AISYS Piezoolectric "o" matrix

TB,PIBZ, 3

TBDATA, 3, -8.9770666

TBDATA, $6,-8.9770686$

TBDATA, 9, 15.523455

TBDATA, 14, 20.800000

TBDATA, 16, 20.800000

\subsection{Program Listing of pzansys.ftn Program}

Here is a listing of the program. The program works through tensor summations, matrix calculations, and matrix inversions. Each subroutine has a one line description and a description of the parameters.

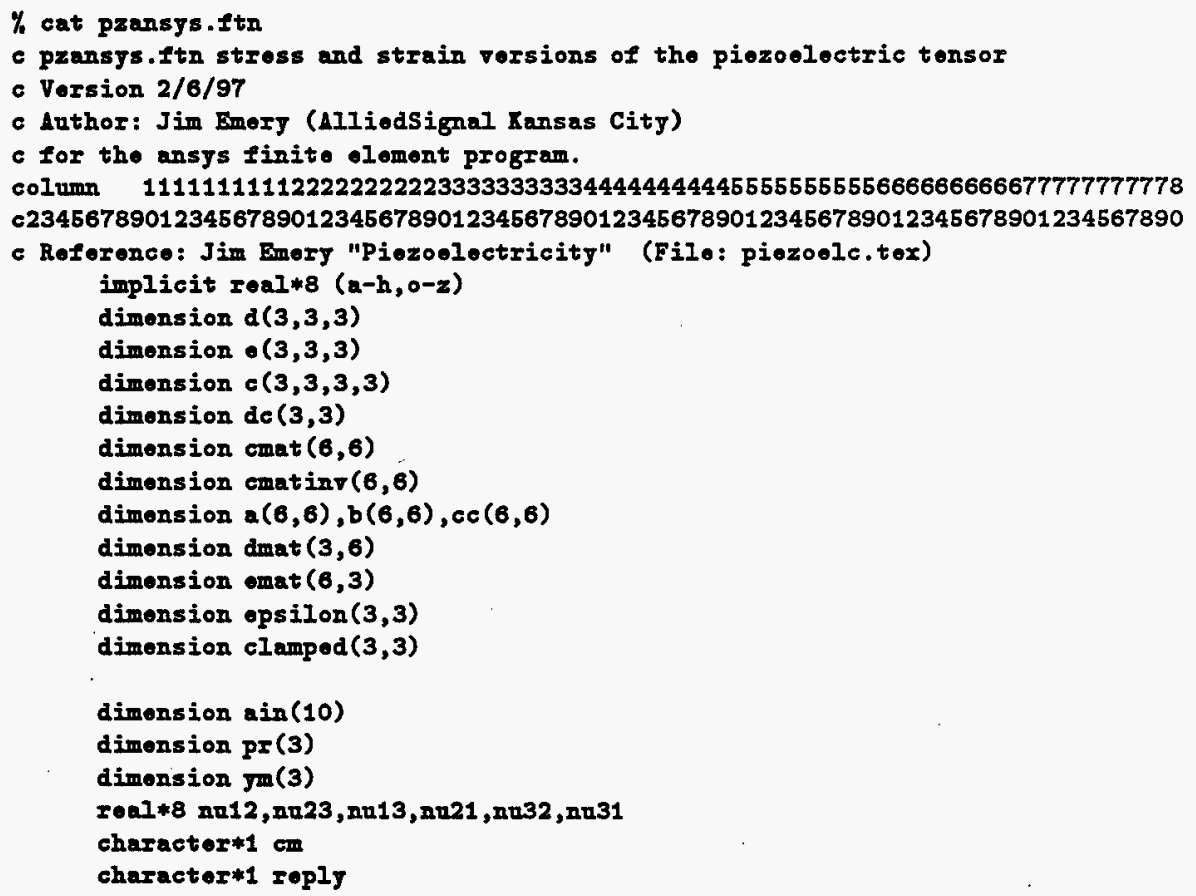




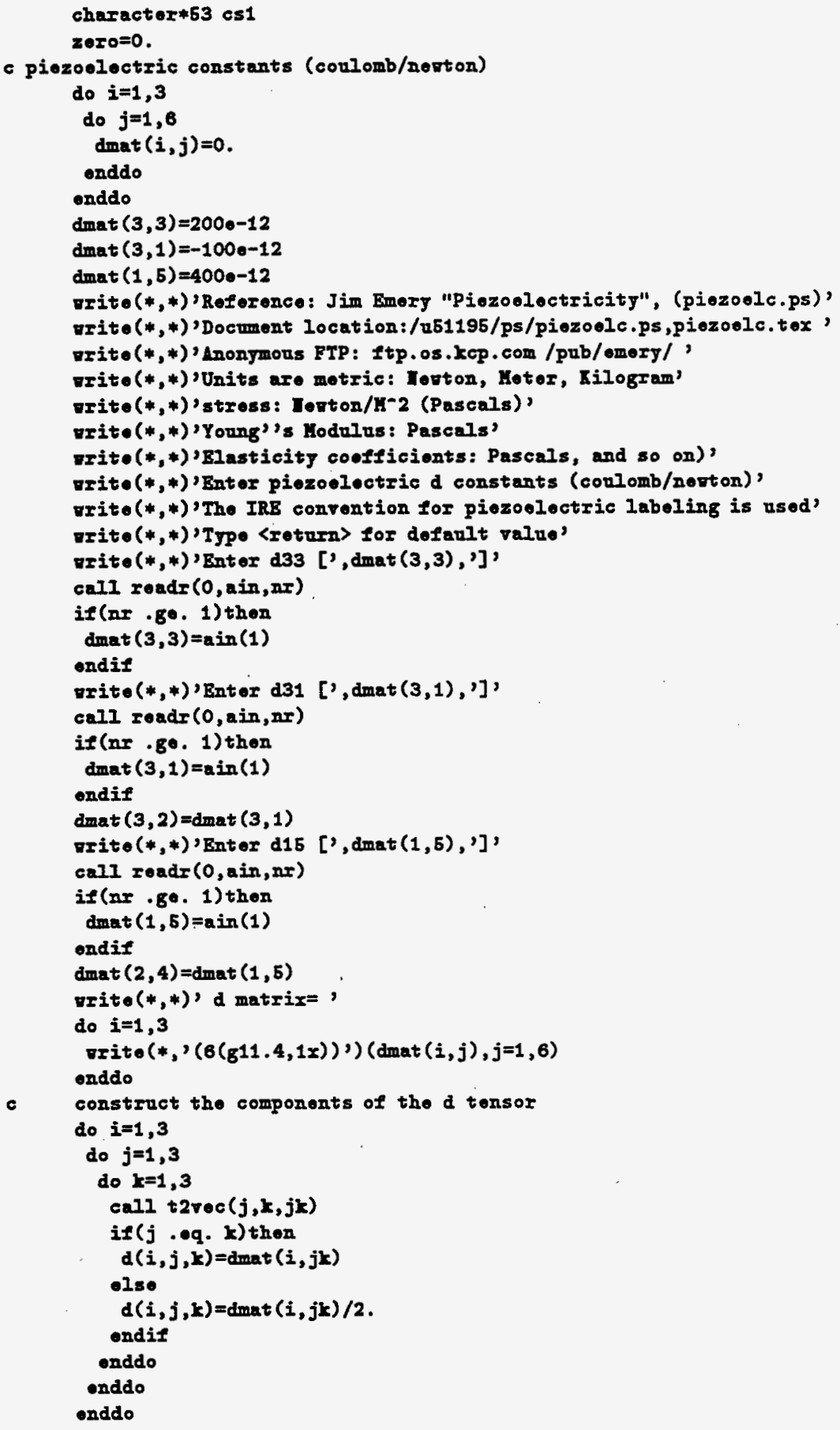




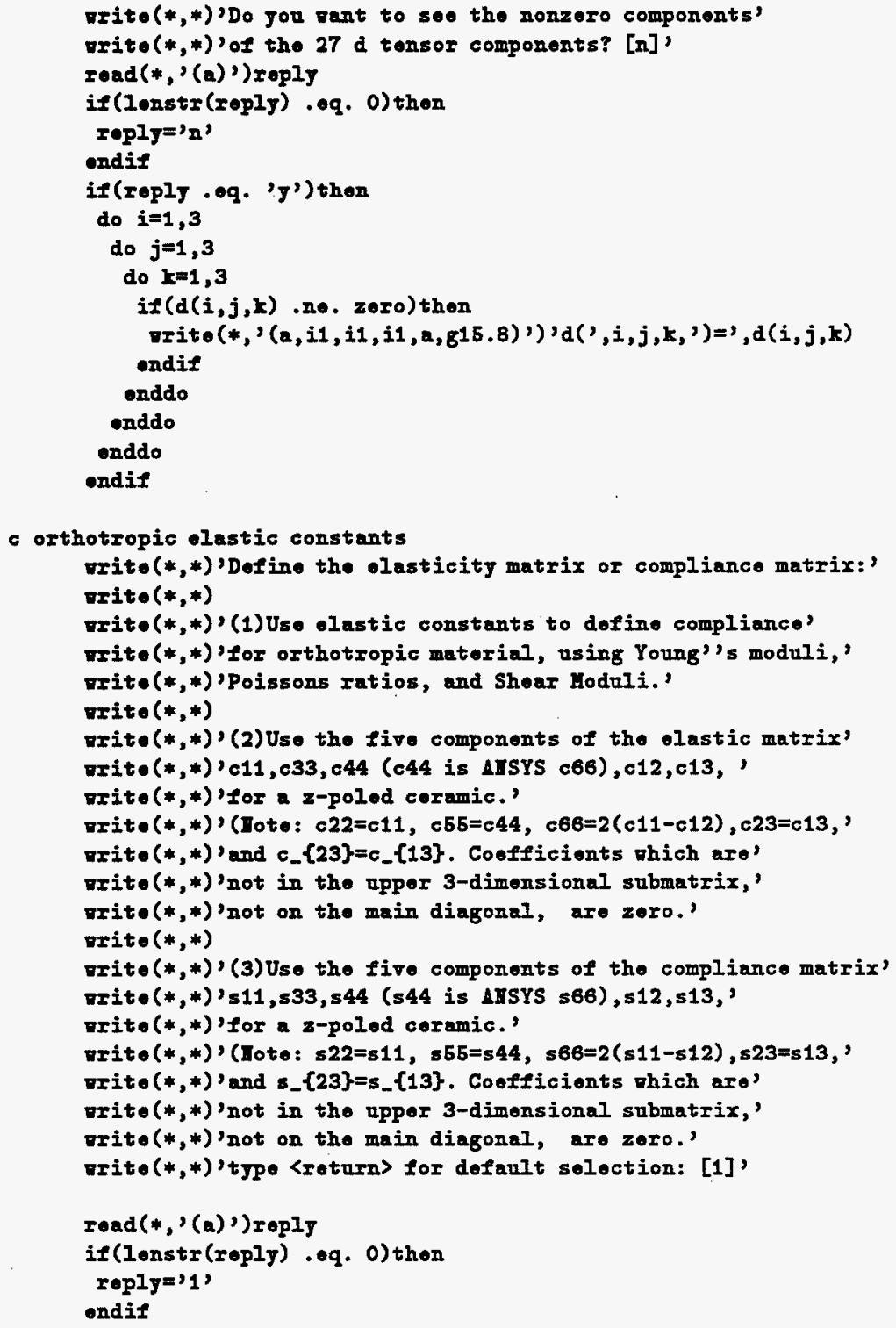

c2345678901234567890123456789012345678901234567890123456789012345678901234567890

c bogin case1

if (roply . •q. '1') then.

write $(*, *)$ 'Enter the orthotropic elastic constants'

urite $(*, *)$ 'for a coordinate system in the principle directions'

$\bullet 1=12.8 \bullet 10$ 


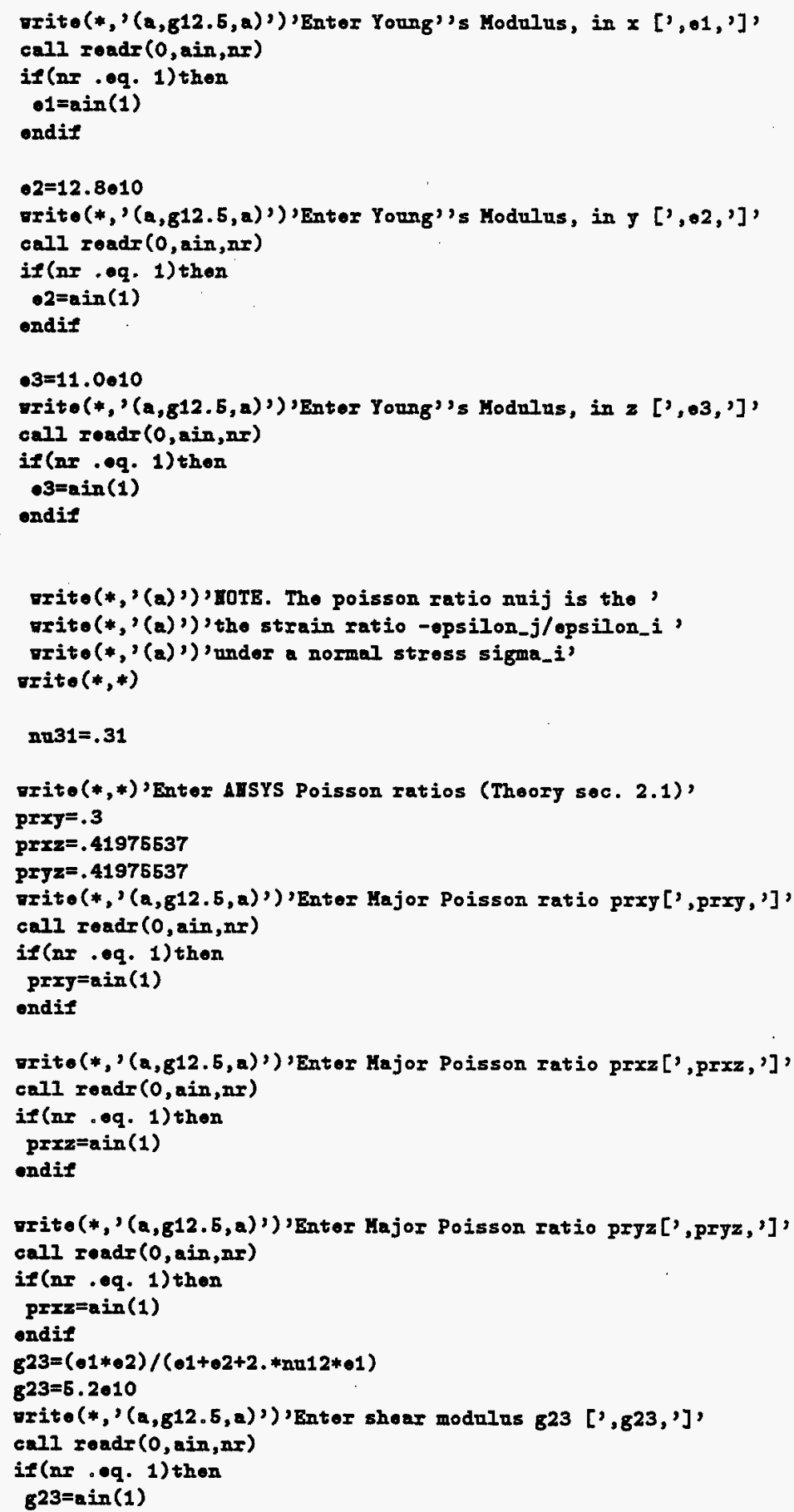


ondif

$c$

$\mathrm{B}^{13}=(\bullet 1 * \bullet 2) /(01+02+2 . * \operatorname{nu} 12 * 01)$

$\mathrm{B} 13=5.2010$

vrite $\left(*, '(a, g 12.5, a)\right.$ ') 'Enter shear modulus $g^{13}\left[', B^{13},{ }^{13}\right.$ '

call roadr $(0$, ain, $n x)$

if (nx .eq. 1) then

$\mathrm{g}^{13}=\mathrm{ain}(1)$

ondif

$c$

$812=(\bullet 1 * \bullet 2) /(\bullet 1+\bullet 2+2 . * \mathrm{nu} 12 * \bullet 1)$

$\mathrm{g} 12=12.2010$

Erite (*,' (a,g12.5,a)')'Enter shear modulus $\mathrm{g}^{12}\left[\mathrm{~g}^{12}, \mathrm{~g}^{12},\right]$ '

call roadr $(0$, ain, $n r)$

if ( $n x$. oq. 1) then

g12=ain (1)

ondit

c

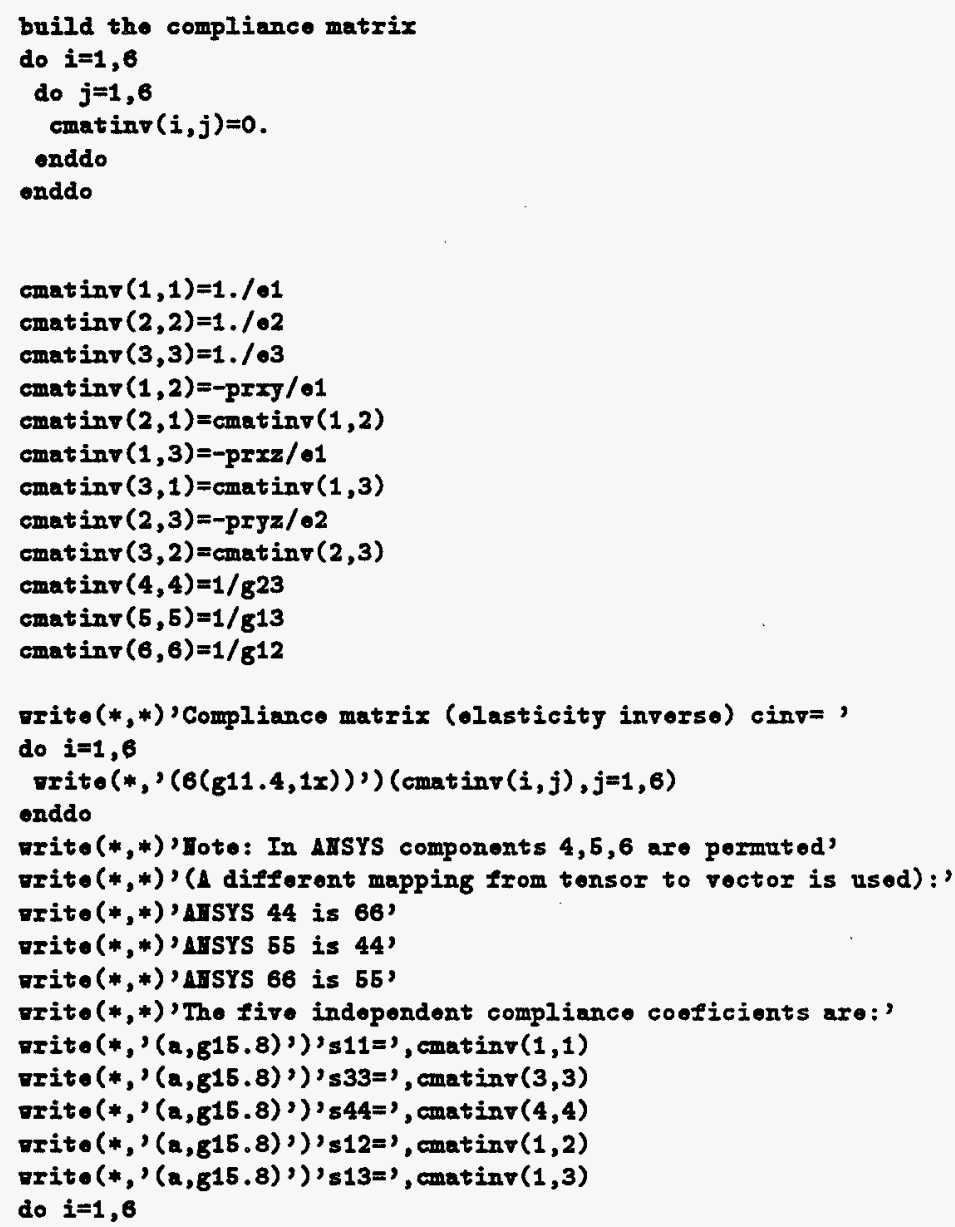




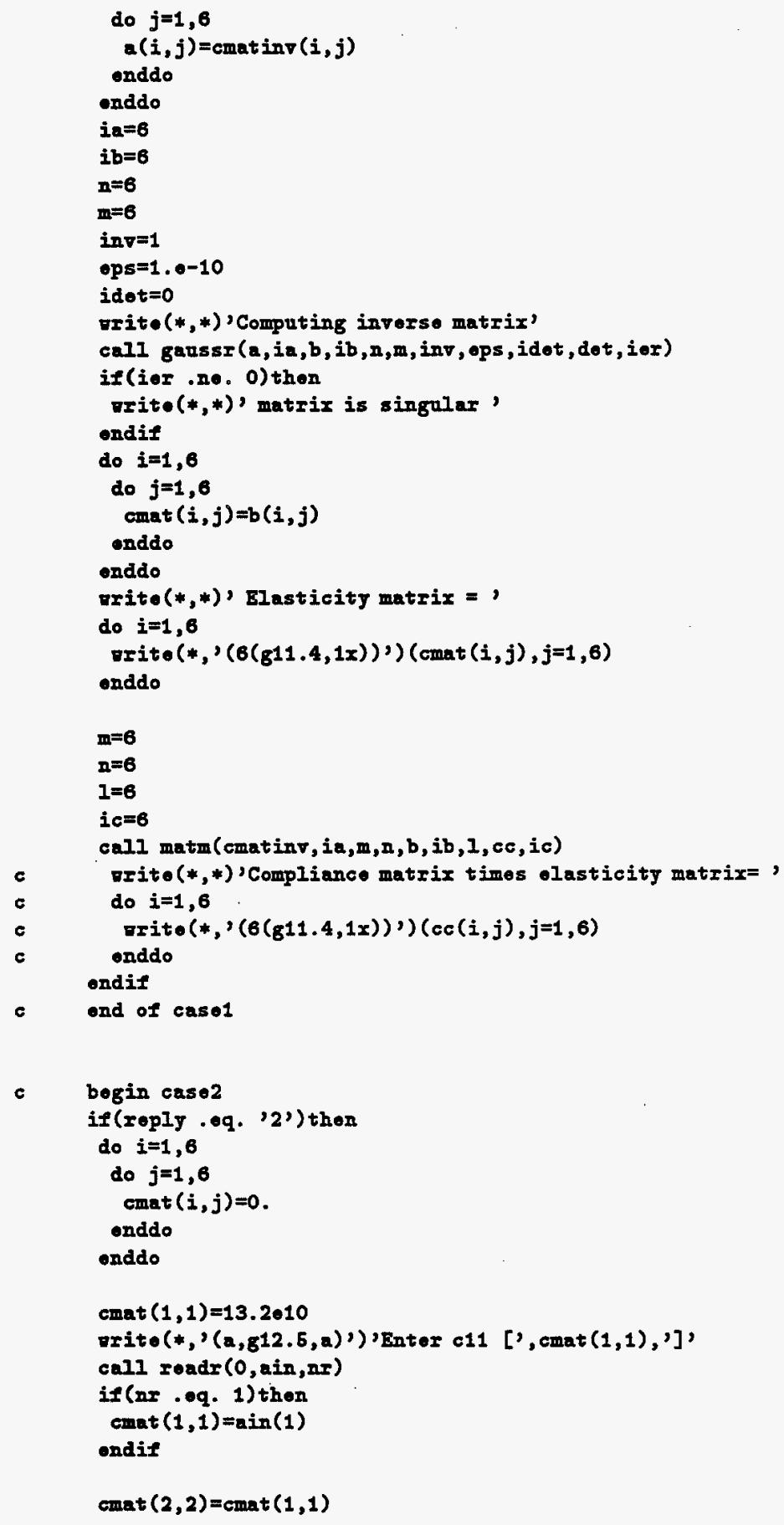




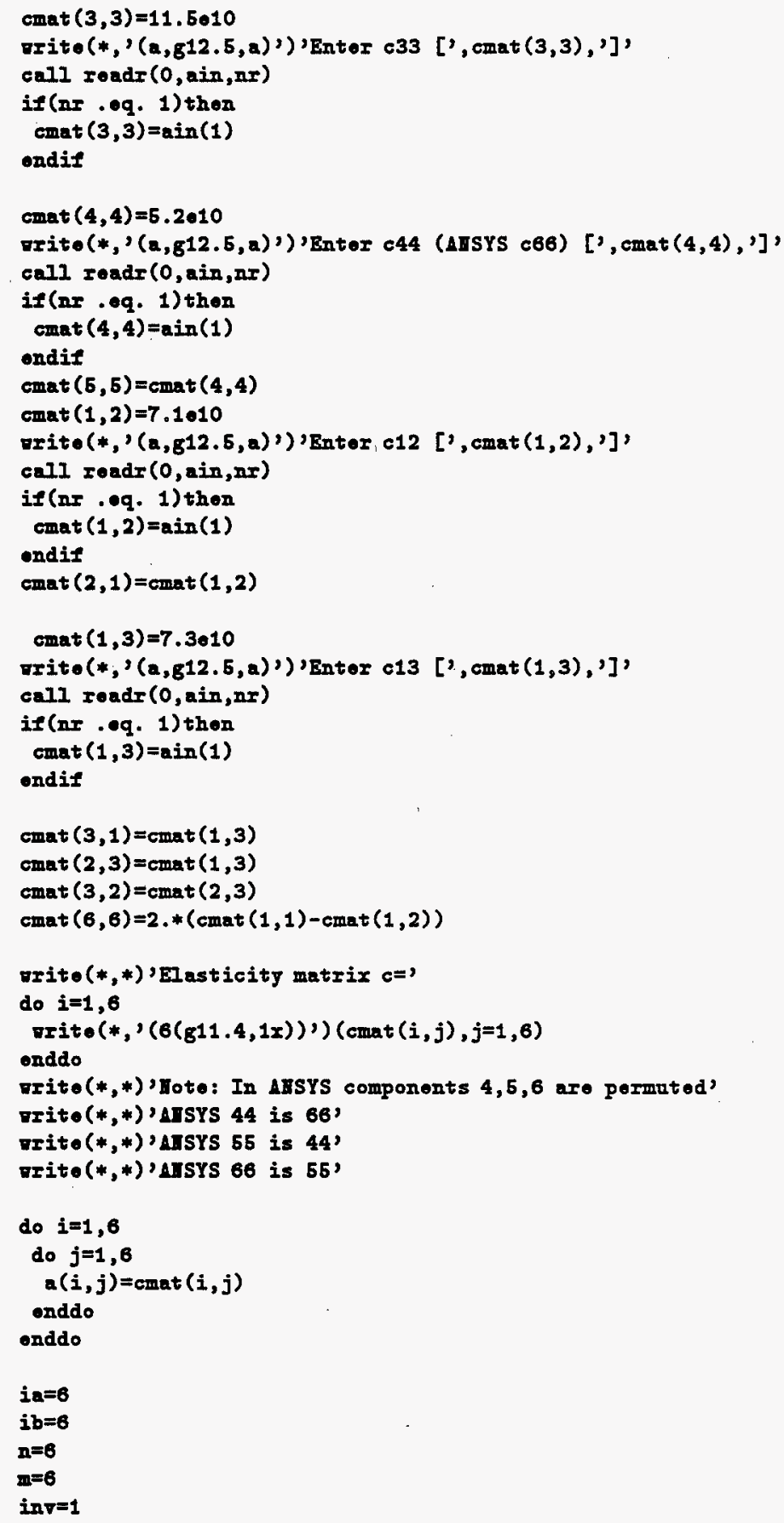




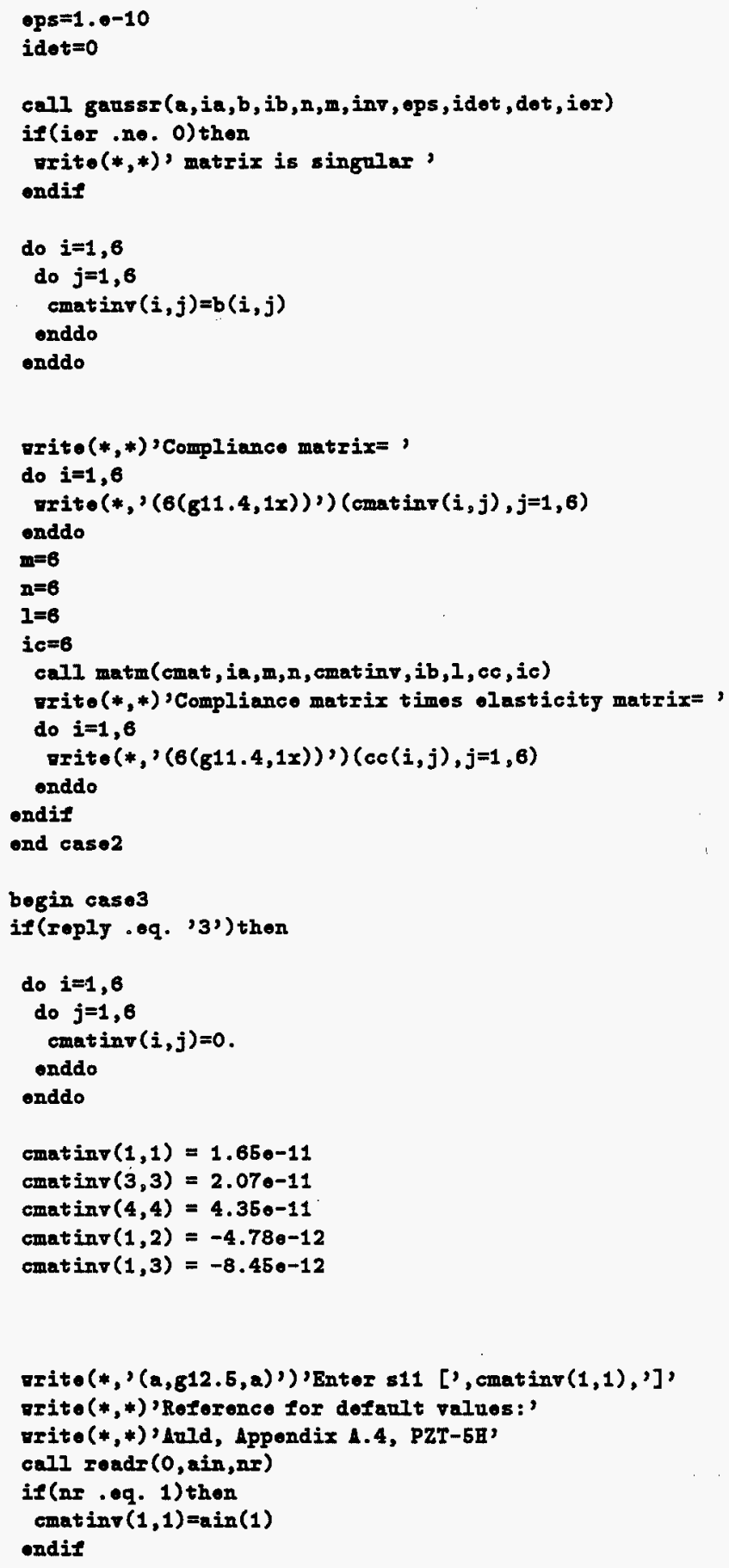




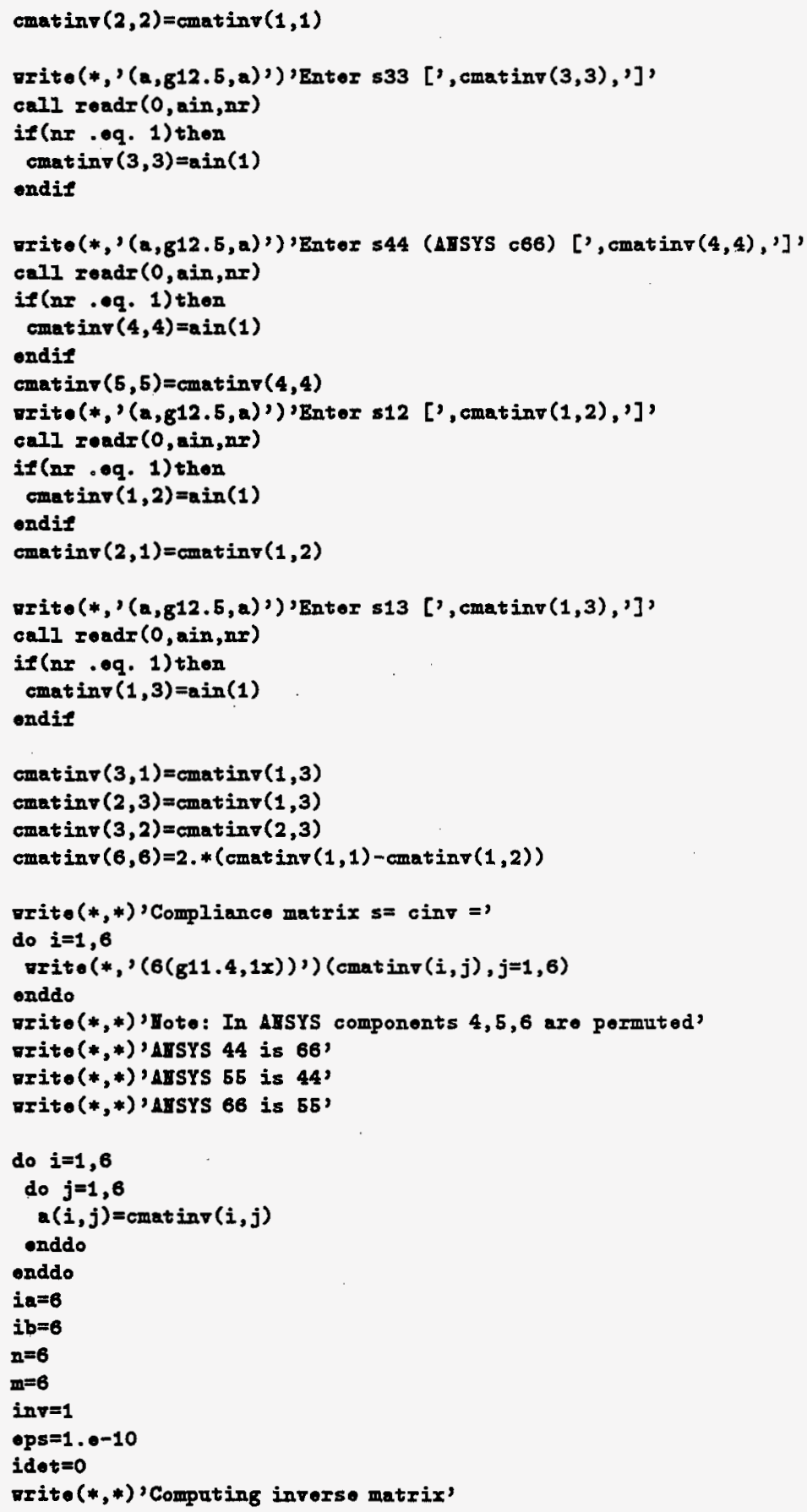




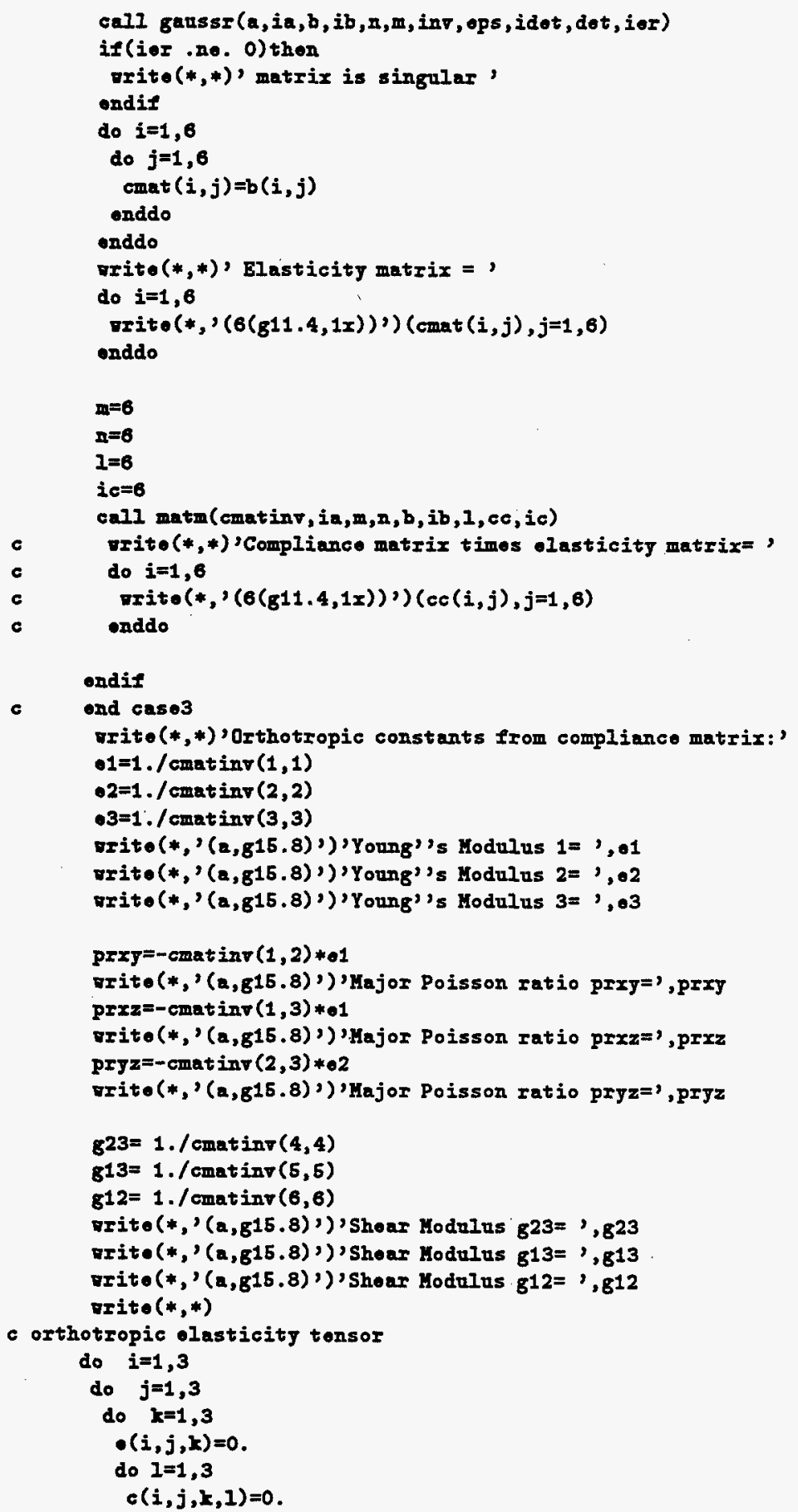




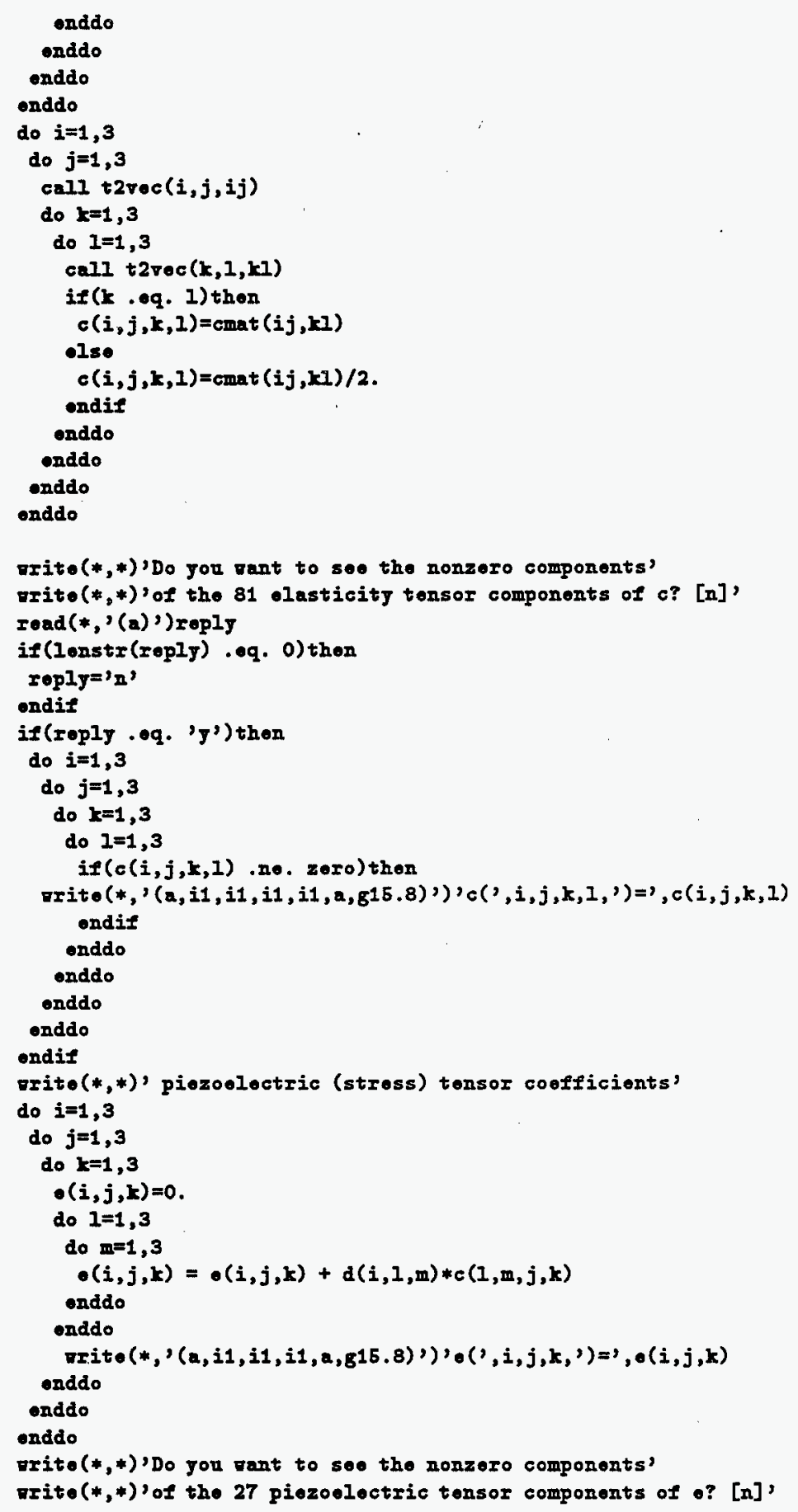




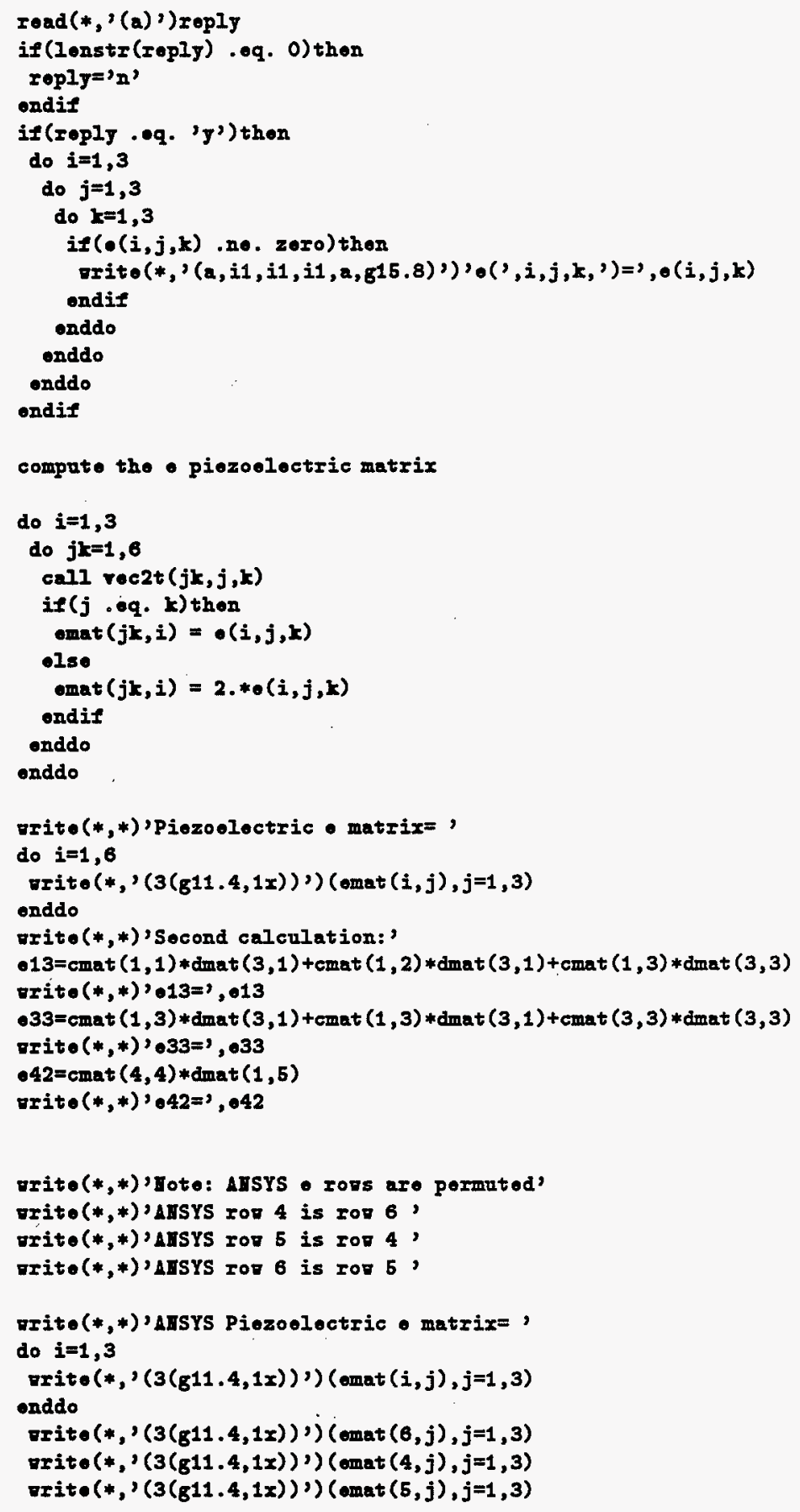

compute the piezoelectric matrix 


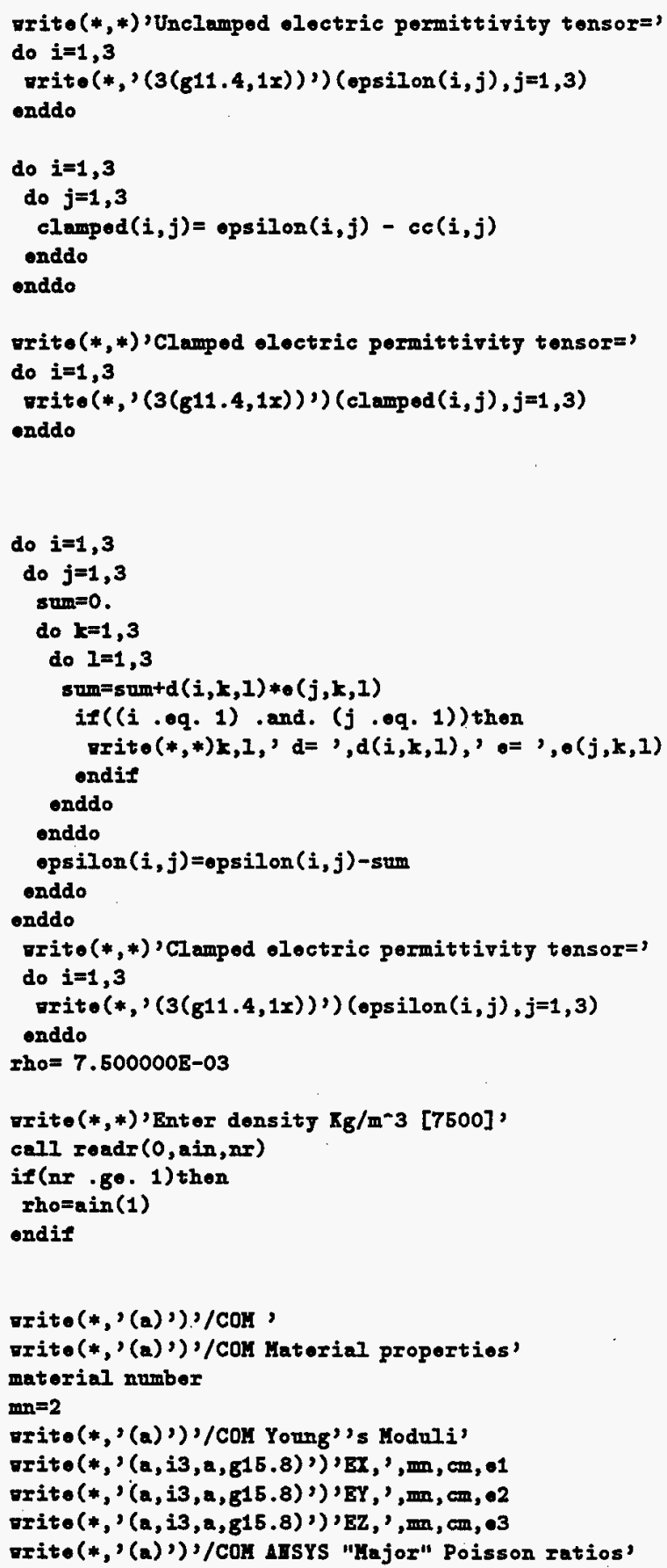


reference AISYS Theory 2.1 structural fundamentals prxy=-cmatinv $(1,2) * 01$

vrite(*, ' $\left(a, i 3, a, g^{15} .8\right)$ ') 'PRXY, ',mn, cm, prxy prxz=-cuatinv $(1,3) * 01$

تrite (*,' (a, i3, a, g15.8)') 'PRXz,',mn, cm, prxz

pryz=-cmatinv $(2,3) * 02$

urite (*,' (a, i3, a, $\mathrm{g}^{15}$.8)') 'PRYZ, ', mn, cm, pryz

arite $\left(*, '(a)\right.$ ') '/COH Density $\mathrm{K}_{\mathrm{g}} / \mathrm{m}-3$ '

rrite (*,' $\left(a, i 3, a, g^{15} .8\right)$ ')'/COM DEIS,', mn, cm, rho

rrite $(*, 2(a)$ ') '/COH clamped Pormitivitios'

c

c

c

opsilon $(1,1)=8.79690-12$

opsilon $(2,2)=8.79690-12$

-psilon $(3,3)=8.79690-12$

rrit• $\left(*, '\left(a, i 3, a, g^{15} .8\right)\right.$ ') 'MP, PERX,', mn, cm, clamped $(1,1)$

urite (*,' $\left(a, i 3, a, g^{15}, 8\right)$ ') 'IPP, PERY,' ,min, cm, clamped $(2,2)$

nrite (*,' (a , i3, $\left.a, \mathrm{~g}^{15} .8\right)$ ') 'MP, PERZ,' ,mn, cm, clamped $(3,3)$

vrite $(*, '(a)$ ') '/COY AMSYS Piezoolectric "e" matrix"

urite $(*, '(a)),, T B, P I B Z, 3$ '

mrite $\left(*, '\left(a, i 3, a, g^{15} .8\right)\right.$ ') 'TBDATA,',3, cm, omat $(1,3)$

rrite $\left(*, '\left(a, i 3, a, g^{15} .8\right),\right)^{\prime}$ 'TBDAIA,', $6, \mathrm{~cm}$, omat $(2,3)$

mrite $\left(*, '\left(a, i 3, a, g^{15} .8\right)\right.$ ') 'TBDATA,',9, cm, omat $(3,3)$

ansys omat $(5,2)=\operatorname{omat}(4,2)$

vrite (*,' (a, i3, a, g15.8)') 'TBDATA,', 14, cm, omat $(4,2)$

ansysemat $(6,1)=\operatorname{emat}(5,1)$

vrite $\left(*, '\left(a, i 3, a, g^{15} .8\right)\right.$ ')'TBDATA,', $16, \mathrm{~cm}$, omat $(5,1)$

end

c+ roadr read a rop of floating point numbers

subroutine readr(nf, a, nr)

implicit $r e a l * 8(a-h, 0-z)$

c numbers are separated by spaces

examples of valid numbers are:

$12.133445 .44 .780-6402,5.6 \mathrm{D}-23,10000 . d 015$

nf=file number, 0 for standard input fil.

$a=a r r a y$ of returned numbers

$n r=n u m b e r$ of values in returned array,

or 0 for empty or blank line,

or -1 for end of file on vit ne.

requires functions val and length

dimension $a(*)$

character $* 200$ b

character*200 c

character*1 d

$c=$,

if (rf. $\circ$. 0) thon

$\operatorname{read}(*,)^{\prime}(a)^{\prime}$, ond $\left.=99\right) b$

-lso

$\operatorname{road}(n f$, ' (a)', ond $=99) b$

ondif

nr $=0$

I=Ienstr (b)

if $(1 . g \circ .200)$ then

rrite(*,*)' error in readr subroutine,

vrito $(*, *)$ ' record is too long,

andit 


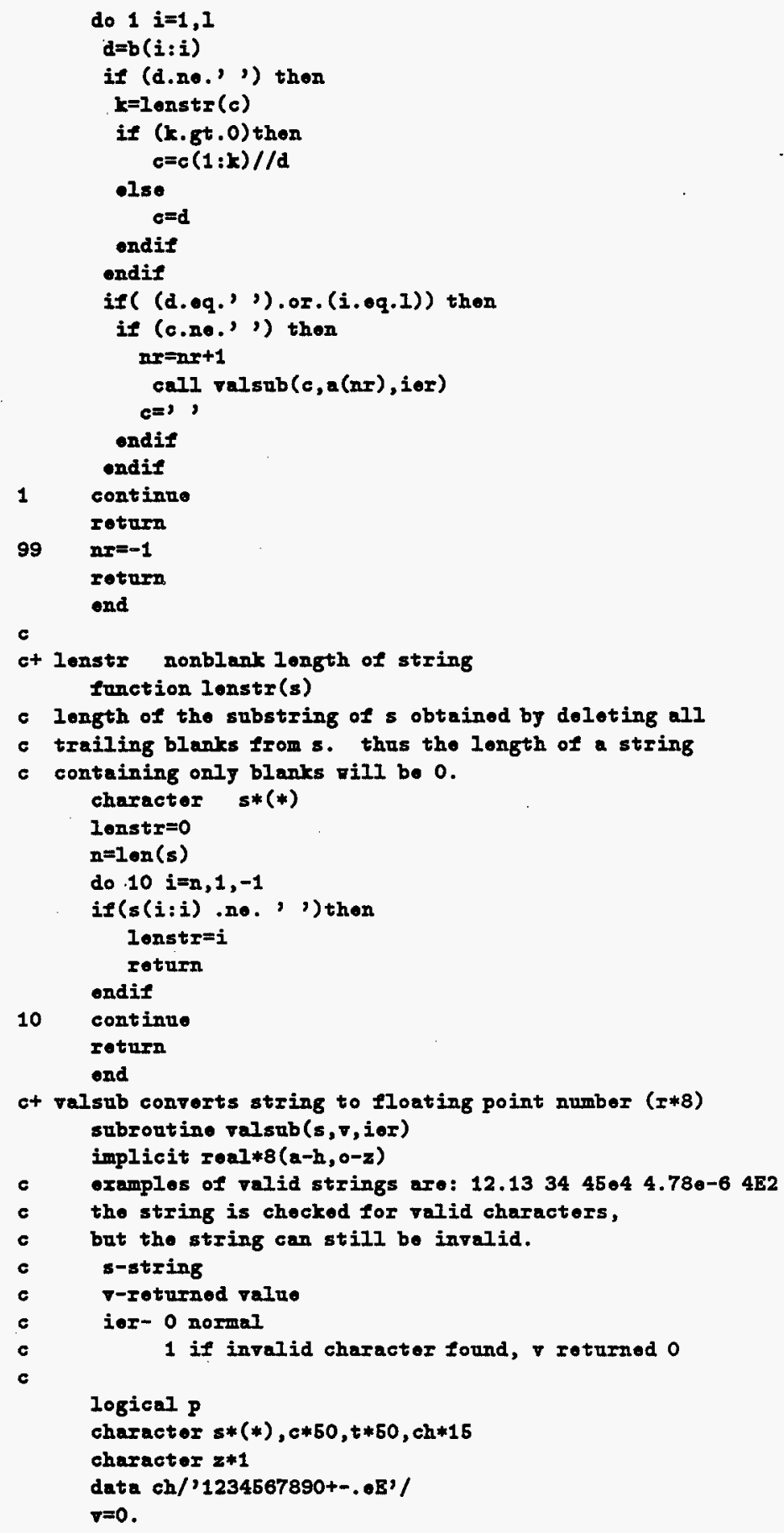




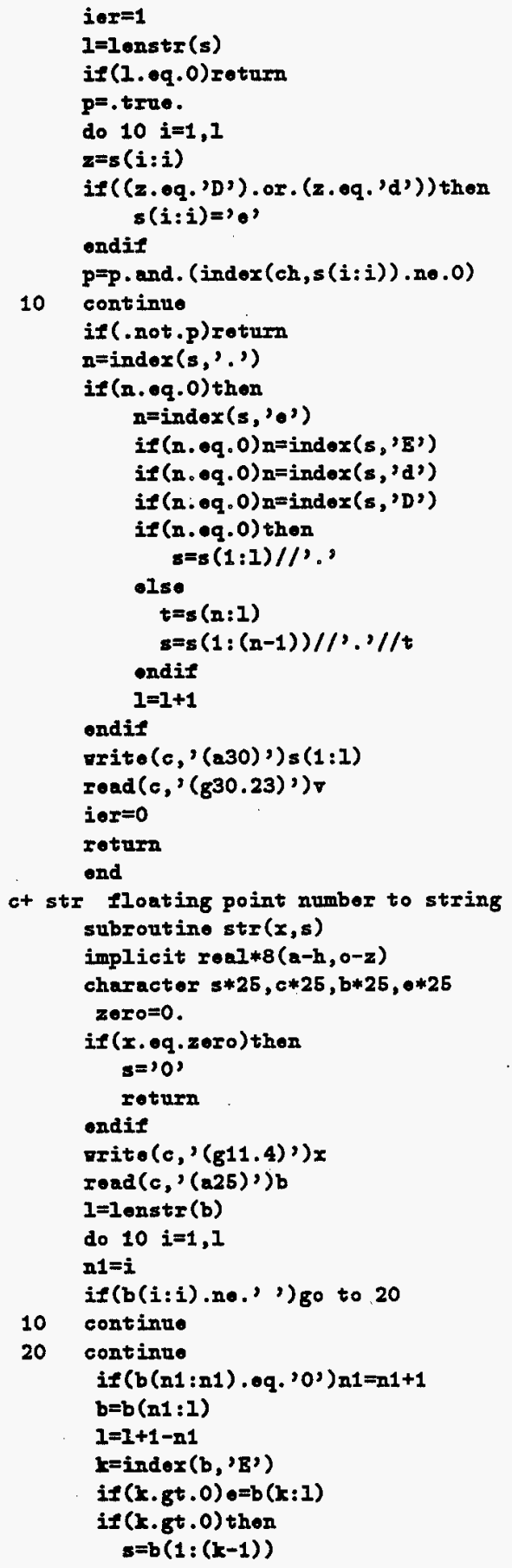




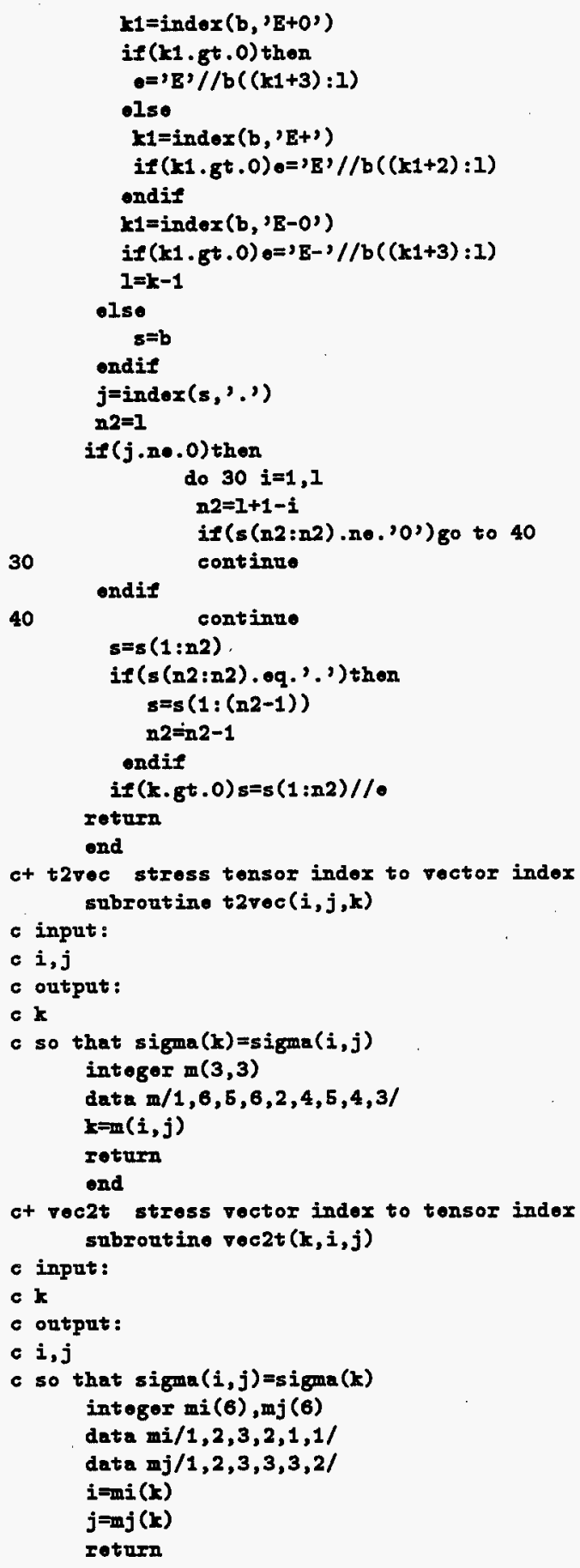


ond

ct gaussr solution of linear equations, inverse, determinent (roul) nor version

c gaussr2.1tn 4/17/96 modernization of gaussr under construction

subroutin॰ gaussr ( $a, i a, b, i b, n, m$, inv, ops, idet, det, ior)

c solves the equation $a * c=b$ for $c$, phere $a$ is an $n$ by $n$ matrix

$c c$ and $b$ are $n$ ror by m column matrices. $c$ is roturnod as b.

algorithm -gaussian olimination vith partial piroting.

c paramoters a-n by n matrix containing tho coofficients of

the linear systom.

ia-rov dimension of a in defining routine

$\bullet . \mathrm{g}$. in the routine vhore $a$ is defined,

a might be dimensioned as:

dimension a $(n x, n c)$

then ia must be sot to $n x$. I0 may have $n<i a$, but

must not have $n>$ ia, or $n * n>n r * n c$.

ia is noeded for proper addressing of matrix a.

fortran stores by colum first: $a(i, j)=a(i+(j-1) * i a)$ )

b-n by m matrix containing the m right sides

of the equations, on entering. on returning, $b$

contuins the solutions. the inverse of $a$ is

roturned in $b$ then inv=1

ib-rov dimension of $b$ in defining routine

$n$-ror and column dimension of $a$.

m-column dimension of $b$ (usually 1 )

the program changes m to $n$ then invel

inr-the inverse of a is calculated

and roturned in $b$ then inv=1

$b$ must be large onough to hold the inverse

ops-oach equation is normalized so that the

coofficionts are $<=1$ in magnitude.

when a pivot is loss than ops the matrix is

considerod noarly singular, and ier is sot to 1

if a pirot is zero the matrix is singular, and

ior is set to 2 . one may set ops $=1.0-5$ for

singlo procision, and 1.e-12 for doublo.

ops doos not offoct ony calculation.

normalization may also prevent exponent overflor.

idet-compnte determinant only if idot $=1$

doterminants are products of $n$ numbers.

ovorflor can occur if the olements of the

matrix have large oxponents.

set idet $=0$ if the determinant is not noeded.

dot-doterminant of a.

ier-roturn parameter,

ier=0 normal roturn

ier=1 matrix is noarly singular

ior $=2$ matrix is singular

varning!! the subroutine changes $a$ and $b$. if they noed to bo

sared, copies must be made before calling the subroutine.

the subroutine can be converted to different number type

by uncomenting the appropriate implicit statement.

implicit real $\neq 8(a-h, 0-z)$

implicit complex $(\mathrm{a}-\mathrm{h}, 0-\mathrm{z})$

c implicit complox*16(a-h,o-z) 


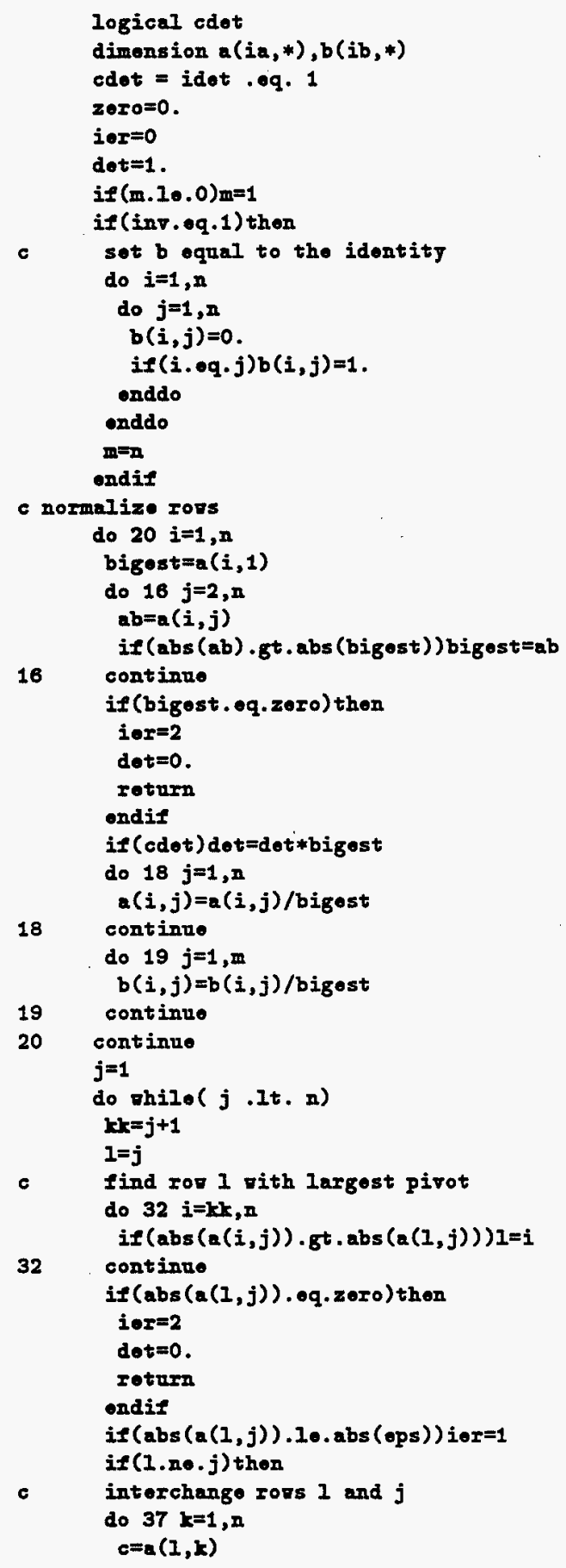




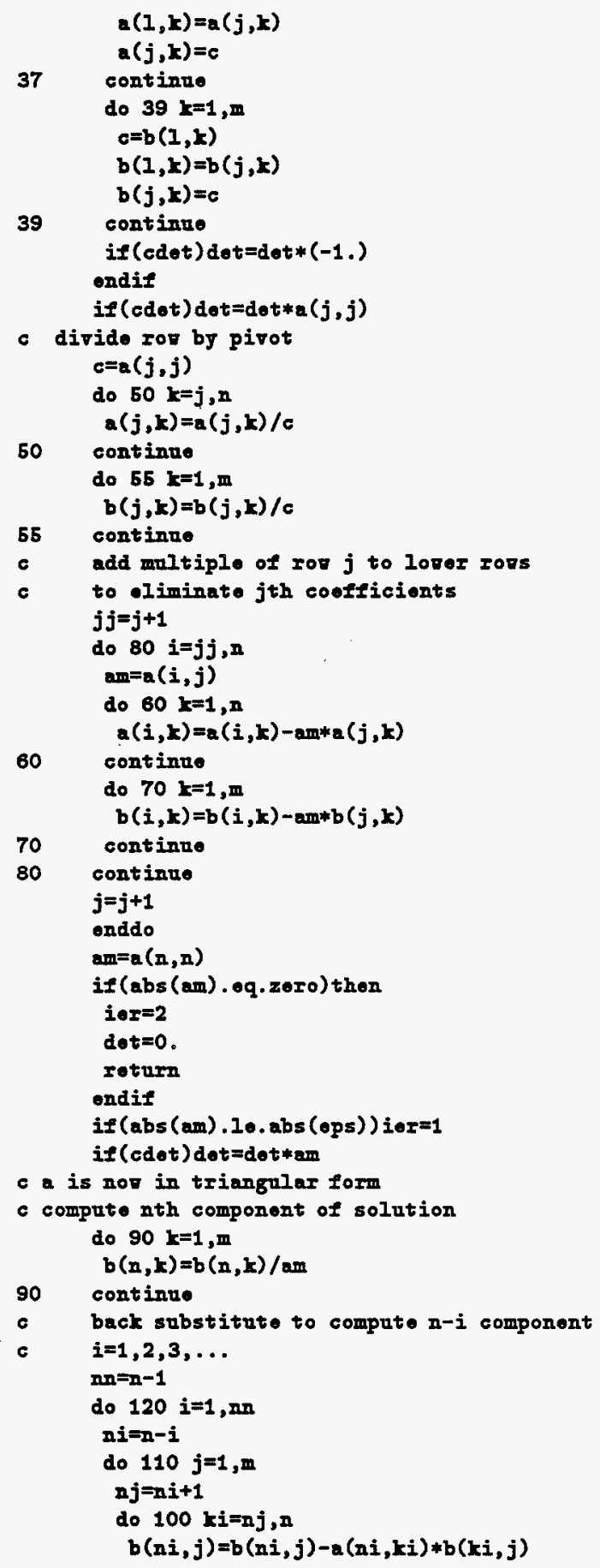




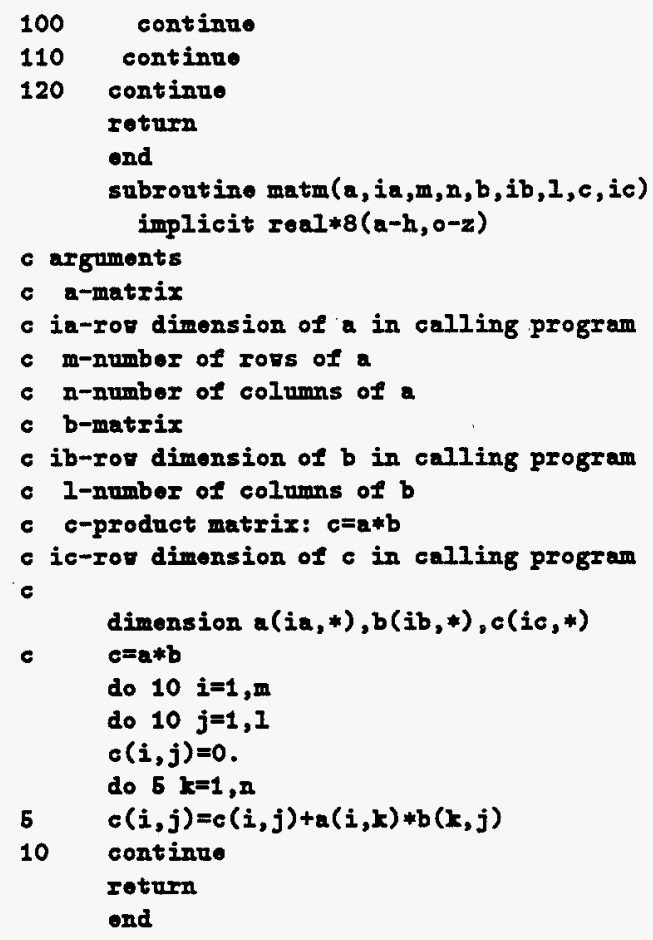

\subsection{Location of Piezoelectric Information In ANSYS Manuals}

- Index assignment for stress-strain tensor to six-vector: Theory 2.1 .

- Major and Minor Poisson ratios, orthotropic compliance matrices: Theory 2.1 .

- Piezoelectric Solid Element SOLID5: Elements manual 4-39.

- Piezoelectric Plane Element PLANE13: Elements manual 4-85.

- Piezoelectric Tetrahedral Coupled Solid Element SOLID98: Elements manual 4-653.

- Piezoelectric Analysis: Procedures Coupled-Field Analysis 8.1, piezoelectric analysis p8-13 to p8-15. 
- Defining matrices: Commands TB and TBDATA, Commands manual.

- Piezoelectrics Theory: Theory Manual 11.1 to page 11-17.

- Example VM175: Natural Frequency of a Piezoelectric Transducer ...(ANSYS Stuff Notebook). Reference: Boucher D, Lagier M, Maerfeld C, IEEE Transactions on Sonics and Ultrasonics, Volume SU-28, No. 5 September 1981 pp318-330.

- Example VM176: Frequency Response of Electrical Admittance for a Piezoelectric Transducer, Reference: Kagawa and Yamabuchi, IEEE Trans. Sonics and Ultrasonics, V. SU-26, No. 2, March 1979.

- Example PM13, ANSYS Examples Supplement, Piezoelectric Beam Resonator

\subsection{ANSYS Comparison For A Compos- ite Piezoelectric Transducer: Example VM176.}

Reference for the problem: Kagawa and Yamabuchi Finite Element Simulation of a Composite Piezoelectric Transducer IEEE Transactions on Sonics and Ultrasonics, Vol. SU-26, No 2 march 1979.

The transducer consists of cylindrical disks of aluminum, adhesive, PZT, adhesive, and aluminum.

PZT material: NEPEC 6

Elasticity matrix

$$
c=10^{10}\left[\begin{array}{cccccc}
12.8 & 6.8 & 6.6 & 0 & 0 & 0 \\
6.8 & 12.8 & 6.6 & 0 & 0 & 0 \\
6.6 & 6.6 & 11 & 0 & 0 & 0 \\
0 & 0 & 0 & 2.1 & 0 & 0 \\
0 & 0 & 0 & 0 & 2.1 & 0 \\
0 & 0 & 0 & 0 & 0 & 2.1
\end{array}\right]
$$


Piezoelectric matrix (Coulomb/Meter ${ }^{2}$ )

$$
e=\left[\begin{array}{ccc}
0 & 0 & -6.1 \\
0 & 0 & -6.1 \\
0 & 0 & 15.7 \\
0 & 0 & 0 \\
0 & 0 & 0 \\
0 & 0 & 0
\end{array}\right]
$$

Dielectric Matrix (Farad/Meter)

$$
\epsilon=10^{-9}\left[\begin{array}{ccc}
8.7969 & 0 & 0 \\
0 & 8.7969 & 0 \\
0 & 0 & 8.7969
\end{array}\right]
$$

See ANSYS notebook for more details. 


\subsection{Piezoelectricity Bibliography}

[1]Agarwal Bhagwan D, Broutman Lawrence, Analysis And Performance Of Fiber Composites.

[2]Ahmed F R, Crystallographic Computing Proceedings International Summer School, Linda Hall Library.

[3]Allik H, Hughes J R, Finite Element Method For Piezoelectric Vibration, International Journal of Numerical Methods For Engineering, V. 2, pp 151-157, 1970, (This is the formulation of the problem that is implemented in ANSYS.)

[4]Ashton J E, Whitney J M, Theory Of Laminated Plates, Linda Hall Library, 1979.

[5]Ashton T E, Halpin T C, Petit P H, Primer On Composite Materials Analysis, Technomic, Stamford Conn., 1969.

[6]Auld B A, Acoustic Fields And Waves In Solids, Volumes I and II. [7]Billington E W, Introduction To The Mechanics And Physics Of Solids, AlliedSignal Library, QA808 .2, 1986, A Mathematical Book. Von Mises Yield Criterion. Von Mises Stress.

[8]Bottom Virgil E, The Theory And Design Of Quartz Crystal Units, 2nd Ed., 1974, (Self Published), Linda Hall, (Piezoelectric Transducers.)

[9]Boucher D, Lagier M, Maerfeld, Computation Of The Vibrational Modes For Piezoelectric Array Transducers Using A Mixed Finite Element-Perturbation Method, IEEE Transactions on Sonics And Ultrasonics, V. Su28, No. 8, Sept 81.

[10]Brebbia, Dewilde,Blain, Computer Aided Design In Composite Material Technology, TA 418.9 .c6 I585, 1988, Linda Hall.

[11]Buchanon Relva C, Editor, Ceramic Materials For Electronics, 2nd Ed., 1991, AlliedSignal Library, (Piezoelectricity.)

[12]Buerger, Martin, Introduction To Crystal Geometry, [13]Cady Walter Guyton, Piezoelectricity, 537.2 C12p, Volumes I and II1, Dover, 1964, KCMO Library.

[14]Cady Walter Guyton, The Piezoelectric Resonator, In: Physical Acoustics, R. Bruce Lindsey Editor, (Benchmark Papers In Acoustics).

[15]Clough R W, Penzien J, Dynamics Of Structures, McGraw-Hill 1972, AlliedSignal Library, (Rayleigh Damping, Piezoelectricity.)

[16]Cracknell A P, Ultrasonics, Wykeham Publications, 1980 AlliedSignal Library. 
[17]Crandall B C, Lewis James, Editors, Nanotechnology, Article: John Foster, p17, Scanning Tunneling Microscope (STM), (Uses Piezoelectric Control,) 1992, MIT Press.

[18]Cullity, Elements Of X-Ray Diffraction, Addison-Wesley, 1956.

[19]Cummings James R, Predicting The Effect Of Thickness Of Piezoelectric Plates On The Performance Of The Ultrasonic Traveling Wave Motor, U. Mo. (Rolla,), May 1993.

[20]Cummings James R, Stutts Daniel S, Dharani L R, Effects Of Material And Geometric Characteristics On The Performance Of $\mathbf{A}$ Traveling-wave Motor, U. MO. Rolla Report, 11-9-93.

[21]Cummings Robert James, Analysis Of The Performance And Contact Behavior Of The Piezoelectric Traveling-wave Motor, Masters Theses, University Of Missouri-Rolla MRTC Manufacturing Research And Training Center, 1994.

[22] Not released

[23] Not released

[24] Not released

[25] Not released

[26] Not released

[27]Flynn Anita, Torque Production In Ultrasonic Motors, MIT Artificial Intelligence Laboratory, January 9, 1994, (Piezoelectric Motor.)

[28]Flynn Anita M, Piezoelectric Ultrasonic Micromotors, PhD Thesis, MIT, June 1995.

[29]Fulton Langdon H, Techniques And Applications Of The Gas Squeeze Film Bearing, Masters Thesis, Moore School, U. Pennsylvania, Dec 1967, (Piezoelectric Application. Now At Martin-Marietta Communications Systems, Camden NJ).

[30]Gooberman G L, Ultrasonics, 1968, Acoustic Impedance, Transmission Lines, Transducers, Equivilent Circuit As Transmission Line, Q Of Transducer.

[31]Goree, Pagano-Goree Free Edge Stress, (Discussion, Goree: Singular Elements In Abaqus Are Needed, Disagreement With Whitney.)

[32] Hagedorn P, Wallashek J, Traveling Wave Ultrasonic Motors, Part I: Working Principle And The Mathematical Modeling Of The Stator, J. Of Sound And Vibration, V. 155, No. 1, pp 31-46, 1992.

[33]Hagood N, Chung W, Von Flotow A, Modeling Of Piezoelectric Ac- 
tuator Dynamics For Active Structural Control, J. Intell. Mat. Syst. And Structures, V. 1, pp327-354, July 1990, (Hamilton's Principal Modified For General Electromechanical Systems.)

[34]Hagood Nesbit, Mcfarland Andrew, Modeling Of A Piezoelectric Rotary Ultrasonic Motor, IEEE Trans. Ultrasonics Ferroelectrics And Frequency Control, V. 42, No. 2, March 1995, Nesbit was Anita Flynn Collegue at MIT. Rayleigh-Ritz Method, which includes Electrical Energy.

[35]Hauptman, Herbert, Crystal Structure Determination, Linda Hall, QD911.h33, 1972, Mathematical Biophysics Department, Medical Foundation Of Buffalo, Cosine Semiinvariants.

[36]Heising Raymond A, Quartz Crystals For Electrical Circuits: Their Design And Manufacture, Van Nostrand, 1946, Reprinted by Electronic Industries Association 2001 Eye St, NW, Washington DC 20006, 1978, 1982, (Piezoelectric Equivalent Circuits.)

[37]Hirose, Takahashi, Uchino, Aoyagi, Tomakawa, Electromechanical Properties Of PbZro3-pbzrtio3-pb(mn(1/3)sb(2/3)o3 Ceramics Under Vibration Level Change, Mat. Res. Soc. Symp. Proc., V. 360, 1995, Materials Research Society.

[38]Hirose, Takahashi, Uchino, Aoyagi, Tomakawa, Measuring Methods For High-Power Characteristics Of Piezoelectric Materials, Mat. Res. Soc. Symp. Proc., V. 360, 1995, Materials Research Society.

[39]Hossack John A, Hayward Gordon, Finite-Element Analysis of 1-3 Composite Transducers, IEEE Transactions on Ultrasonics, Ferroelectrics, and Frequency Control, V. 38, N0. 6, November 1991, (Uses ANSYS.)

[40]Inman Daniel, Engineering Vibration, MatLab Disk, 1994, Chapter: Experimental Modal Analysis.

[41]Institute of Radio Engineers, IRE Standards on Piezoelectric Crystals: Determination of the Elastic, Piezoelectric, and Dielectric Constants, The Electromechanical Coupling Factor, 1958, Proc. IRE, V. 46, pp764-78.

[42]Jaffe Bernard, Cook William, Jaffe Hans, Piezoelectric Ceramics, Academic Press, 1971, Linda Hall, TK7871.15.C4 J3, Definitions, Symmetry, Constants, Measurements, Hysteresis.

[43]Johnson K L, Contact Mechanics, Linda Hall Library.

[44]Jones, Acoustic And Electromagnetic Waves, Oxford.

[45]Kagawa, Yamabuchi, Finite Element Simulation of a Composite Piezoelectric Transducer, IEEE Transactions on Sonics and, Ultrasonics, 
V. SU-26, No. 2 march 1979, (ANSYS example VM176.)

[46]Kikuchi And Oden, Contact Problems In Elasticity: A Study Of Variational Inequalities And Finite Element Methods, Linda Hall, QA931.k47 1988, (SIAM), Society For Industrial And Applied Mathematics. [47]Kittle, Solid State Physics, (Piezoelectric Equations.) [48]Koehler D R, Radial Vibration Modes In Thin Plates Of $\mathrm{BaTiO}_{3}$ And $\mathrm{LiNBO}_{3}$, Memo, Sandia National Laboratory, October 16, 1989. [49]Koiter W T , Miknailor G K, Theory Of Shells, [50]Kolsky, Stress Waves In Solids, Dover.

[51]Kompaneyts A S, Theoretical Physics, Dover, 1961.

[52]Lass Victor Vector And Tensor Analysis, (Relation Between Mechanical, Electric, And Magnetic Energy.)

[53]Lazan B J, Damping Of Materials And Members In Structural Mechanics, Oxford 1968.

[54]Lerch, R, Simulation Of Piezoelectric Devices By Two And Three Dimensional Finite Elements, IEEE Trans. On Ultrasonics Ferroelectrics And Freq. Control, V. 37, No. 2, May 1990.

[55]Levich B G, Theoretical Physics, Volumes I, Ii, Iii, Wiley-Interscience 1971.

[56]Lur'e A L, Three-dimensional Problems Of Elasticity, (Basis Of James Cummings Rolla Analysis Of Tooth Contact In Piezo Motor).

[57]Mansfield, E H, The Bending And Stretching Of Plates, (The Small Deflection Theory Of Plates Is Analogous To Beam Small Deflection Theory. Gaussian And Mean Curvature, Where Curvature Is Taken To Be Approximated By The 2nd Order Derivatives. Twist Is The Cross Derivative. Transformation Matrix For Curvatures Handled As In JRC (above). [58]Marsden Jerrold, The Mathematical Theory Of Elasticity, (Contains Much Differential Geometry).

[59]Martin, Transformation Geometry, (Symmetry Groups, Transformations).

[60]Mason Warren P, Piezoelectric Crystals and Their Application to Ultrasonics, Van Nostrand, 1950.

[61]Mason Warren P, Physical Acoustics, 1964 Academic, AlliedSignal Library, QC225.m3, (Piezoelectric Actuators.)

[62]Mcfarland, Smith, Bernhart, Analysis Of Plates, Linda Hall Library. [63]McLachlan N W, Theory Of Vibrations, Circular Membrane, Circular Plate, Bessel Functions p 129-144. 
[64]Meirovitch Leonard, Elements Of Vibration Anlysis, Mcgraw-Hill, 1975.

[65]Meirovitch, Leonard, Analytical Methods Of Vibration, Vibration Of Plates p 179, Eigenvalues, Rayleigh Quotient, The Biharmonic Equation. [66]Mentesana C P, Optical Stronglink Development And Piezoelectric Motor Evaluation, AlliedSignal KCD, Kcp-613-4573, May 1992.

[67]Mercer C D, Reddy B D, Eve R A, Finite Element Method For Piezoelectric Media, UCT/CSIR Applied Mechanics Research Unit, Technical Report No. 92, April, 1987.

[68]Merhaut Josef, Theory Of Electroacoustics, 1976, Czech Book, Johnson County Library, (Piezoelectric Transducers.)

[69]Mikhlin, S.g, Variational Methods In Mathematical Physics, Linda Hall Library, 1964.

[70]Mizushima Masataka, Theoretical Physics, John Wiley, 1972, AlliedSignal, (From Classical Mechanics To General Relativity, Relativistic Quantum Mechanics And Group Theory.)

[71]Moore And Christopher Davis And Coplan, Building Scientific Apparatus, (Experimental Techniques.)

[72]Morgan Matroc Incorporated, Guide To Modern Piezoelectric Ceramics, Catalog, Vernitron Division.

[73]Morse, Philip M, Vibration And Sound.

[74]Musikant Solomon, What Every Engineer Should Know About Ceramics, 1991, Marcel Dekker, AlliedSignal Book.

[75]Newnham R E, Trolier-McKinstry S, Giniewicz J R, Piezoelectric, Pyroelectric And Ferroic Crystals, J. Material Education, 15, pp 189-223 (1993), (Reprint: Penn State MRL Annual Report To ONR 1994, Appendix 1).

[76]Nye J F, Physical Properties Of Crystals, QD931 .N8, 1957, 1987. [77]Ostergard D, Pawlak T, Three-Dimensional Finite Elements For Analyzing Piezoelectric Structures, Proceedings IEEE Ultrasonics Symp., Williamsburg, Va, 1986, pp 639-642.

[78]Paganno N J, Pipes R B, Interlaminar Stresses In Composite Laminates Under Uniform Axial Extension, Journal Of Composite Materials, V. 4, 1970, pp 538-548.

[79]Paganno N J, Pipes R B, The Influence Of Stacking Sequence On Laminate Strength, Journal Of Composite Materials, V. 5, 1971, pp 50-57. [80]Panasonic, Ultrasonic Motor, Panasonic Electric Motor Division, Mat- 
sushita Electric Industrial Co. Ltd., (Equivalent Circuit.)

[81]Parker Sybyl, Solid State Physics Sourcebook, [82]Press, Flannery, Teukolsky, Numerical Recipes in Fortran, (Subroutines For Computing Bessel Functions.)

[83]Pressly Robert B, Mentesana Charles P, Piezoelectric Motor Development At AlliedSignal Kansas City Division, KCP-613-5515, November, 1994 (Available from NTIS).

[84]Puppo A. H. Evenson H A, Journal Of Composite Materials, V. 4, 1970, pp 201-214.

[85]Raju P. Narayana, Vibration Of Annular Plates, Journal Of The Aeronautical Society Of India, V. 14, No. 2, May, 1962, (Boundary Conditions For Maple Motor Code).

[86]Ramachandran G N , Srinivasan R, Fourier Methods In Crystallography, Linda Hall Library, 1970.

[87]Rayleigh Lord The Theory Of Sound, Volumes I and II, Dover, (Vibrations Of Plates: Chapter 10, p 352, Origin of Rayleigh Damping Concept). [88]Roiguiskis, Bansevicius, Barauskas, Kulviets, Vibromotors For Precision Microrobots, AlliedSignal Library, (Many Kinds Of Piezoelectric Motor Designs.)

[89]Saigoh Hiroaki, Kawasaki Mayumi, Maruko Nobuhiro, Kanayama Kouichi, Multilayer Piezoelectric Motor Using The First Longitudinal And Second Bending Vibrations, Japanese J Applied Physics, V. 34, 1995, pp2760-2764.

[90]Sands Donald E, Introduction To Crystallography, 1975, Dover. [91]Sashida Toshiiku, Kenjo Takashi, An Introduction To Ultrasonic Motors, Oxford U. Press 1993, Piezoelectricity. [92]Sawyer C B, Tower C H, Phys. Rev. 35, (1930) pp269-73, (Technique For Displaying Ferroelectric-Piezoelectric Hysteresis Curves.)

[93]Sherrit S, Gauther N, Wiederick H D, Mukherjee B K, Accurate Evaluation Of The Real And Imaginary Material Constants For A Piezoelectric Resonator In The Radial Mode, Ferroelectrics, 1991, V. 119, pp17-32.

[94]Shields John Potter, Basic Piezoelectricity, 1966, Sams, QC595 .S4, Linda Hall Library.

[95]Smits Jan G, Iterative Method For The Accurate Determination Of The Real And Imaginary Parts Of The Materials Coefficients Of Piezoelectric Ceramics, Trans. Sonics Ultraacoustics. V. Su-23, No. 
6, Nov. 1976, pp393-402.

[96]Soedel Werner, Vibrations Of Shells And Plates, 1981. Second Edition 1993, University Illinois At Chicago.

[97]Sokolnikoff I S, Mathematical Theory Of Elasticity, 1956, (Biharmonic Equation p77. Two Dimensional Problems Ch. 5. Finite Differences, Relaxation Methods, pp442-454.)

[98]Southwell R V, Theory Of Elasticity.

[99]Stoker, Nonlinear Vibrations.

[100]Stutts Daniel, Loss Factors, FAX: Feb 23, 1996, Various Materials Loss Coeficients vs Young Modulus. Comparison Of Damping for a Variety of Metals. Magnetoeleastic Damping In Ferromagnetic Metals. Internal Friction Vs Strain Amplitude. Experimental Setup With Pucot Drive Crystal And Specimin.)

[101]Stutts Daniel, Modal Analysis Of The Free-Free Rod With Damping, FAX: April, 9 1996, (See Piezo96 Notebook.)

[102]Stutts Daniel, A Simple Example Of The Relationship Between Electromechanical Coupling And Measured Impedance, Unpublished Document, University of Missouri at Rolla, Mechanical Engineering Department March 1, 1995.

[103]Stutts Daniel, The Free-free Annular Plate, Maple Program And Document, U. Mo. Rolla Mech. Eng. Dept, January,1994.

[104]Stutts Daniel S, Friend James R (Formerly Cummings), Quarterly Report: Piezoelectric Motor Project, Oct. 21995 (tooth Motion, Asymmetry, Maple Conference, Contact Mech, Web Page).

[106] Takahashi Sadayuki, Herose Seiji, Uchino Kenji, Oh Ki-Young, Electromechanical Characteristics Of Lead-Zirconate-Titanate Ceramics Under Vibration Level Change, 1995 IEEE.

[107]Takuro Ikeda, Fundamentals Of Piezoelectricity, (Electromechanical Coupling Coefficient, X-cut, Y-cut Plate, Equivalent Circuit. p84.)

[108]Termin, Radio Engineering, (Equivalent Circuit Of Piezo Oscillator.) [109] Tiersten H F, Linear Piezoelectric Plate Vibration, Plenum Press, 1969, pp33-99, (Fundamental Equations And Equivalent Circuit.) [110] Timoshenko And Goodier, Theory Of Elasticity, Third Edition. [111] Timoshenko, And Woinowsky-Krieger, Theory Of Plates And Shells, 2nd Ed.

[112]Tomikawa Y, Ueha S, Ultrasonic Motors: Theory And Application, Oxford 1993, 
[113]Tuinenga Paul, Spice, A Guide To Circuit Simulation And Analysis Using Pspice.

[114]Tzou H S, Piezoelectric Shells, Kluwer Academic Publishers, 1993.

[115]Urick Robert J, Principles Of Underwater Sound, 2nd Ed., McGrawHill, 1975 (Piezoelectric Transducers.)

[116]Van Randeraat J, Setterington R E, Piezoelectric Ceramics, London, Mullard, Linda Hall Library, 1974.

[117]Voyiadjis, Karamanlidis, Editors, Advances In The Theory Of Plates And Shells, Linda Hall Library.

[118]Wallashek Jorg, Piezoelectric Ultrasonic Motors, Conference On Mechatronics And Robotics, Duisburg/Moers, Germany, Sept 27-29, 1993 pp107-125.

[119]Webb S, The Physics Of Medical Imaging, 1988, Ultrasound, NMR, CT, Tomography.

[120]Weinberger, Hans Partial Differential Equations, (Sturm-Liouville Problems, pp182-187, Circular Membrane, Bessel Functions.)

[121]Weinberger, H F, Variational Methods In Boundary Value Problems, 1961.

[122]Wert, Thomson, Physics Of Solids.

[123]Whitney J M, Browning C E, Journal Of Composite Materials, V. 6, April 1972, pp 50-57.

[124]Whitney J M, Stansbarger D L, Howell H B, Journal Of Composite Materials, V. 5, April 1971, pp24-34.

[126]Whitney James $M$, Structural Analysis Of Laminated Isotropic Plates, 1987, Technomic, (Includes Lampcal Software.)

[127]Whitney, Pipes, Experimental Mechanics Of Fiber Reinforced Composite Materials, 1982, T-C Publishers.

[128]Willmore, T J, Tensors As Tensor Products, QA641.W5, Linda Hall, 1959.

[129]Woolett Ralph S, Theory Of Piezoelectric Flexural Disk Transducers With Applications To Underwater Sound, USL Report No. 490, U. S. Navy Underwater Sound Laboratory, Fort Trumbull, New London Conn, 1960, S-F001 03 04-1.

[130]Wooster, W A, Breton A, Experimental Crystal Physics, KCMO Library.

[131]Yang, Variational Formulation Of Piezoelectric Elements.

[132]Ziman J M, Principles Of The Theory Of Solids, Cambridge, 1964, (Second Edition 1979). 


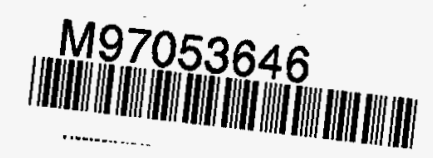

Report Number (14) KCP- $613-5953$

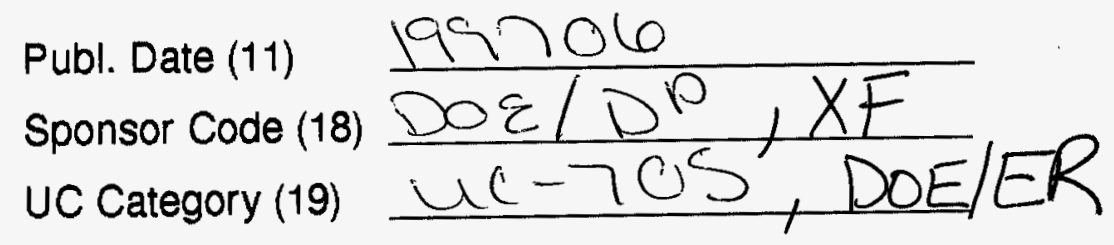

